ARTICLE

Received 20 Aug 2014 | Accepted 30 Oct 2014 | Published 10 Dec 2014

DOI: $10.1038 /$ ncomms6715

OPEN

\title{
Oncogenic Kit signals on endolysosomes and endoplasmic reticulum are essential for neoplastic mast cell proliferation
}

Yuuki Obata1, Shota Toyoshima1', Ei Wakamatsu¹, Shunichi Suzuki ${ }^{1}$, Shuhei Ogawa ${ }^{1}$, Hiroyasu Esumi ${ }^{2,3}$ \& Ryo Abe ${ }^{1}$

Kit is a receptor-type tyrosine kinase found on the plasma membrane. It can transform mast cells through activating mutations. Here, we show that a mutant Kit from neoplastic mast cells from mice, Kit(D814Y), is permanently active and allows cells to proliferate autonomously. It does so by activating two signalling pathways from different intracellular compartments. Mutant Kit from the cell surface accumulates on endolysosomes through clathrin-mediated endocytosis, which requires Kit's kinase activity. Kit(D814Y) is constitutively associated with phosphatidylinositol 3-kinase, but the complex activates Akt only on the cytoplasmic surface of endolysosomes. It resists destruction because it is under-ubiquitinated. Kit(D814Y) also appears in the endoplasmic reticulum soon after biosynthesis, and there, can activate STAT5 aberrantly. These mechanisms of oncogenic signalling are also seen in rat and human mast cell leukemia cells. Thus, oncogenic Kit signalling occurs from different intracellular compartments, and the mutation acts by altering Kit trafficking as well as activation.

\footnotetext{
${ }^{1}$ Division of Immunobiology, Research Institute for Biomedical Sciences, Tokyo University of Science, Noda, Chiba 278-0022, Japan. ${ }^{2}$ Division of Clinical Research, Research Institute for Biomedical Sciences, Tokyo University of Science, Noda, Chiba 278-0022, Japan. ${ }^{3}$ National Cancer Center Hospital East, Kashiwa, Chiba 277-8577, Japan. Correspondence and requests for materials should be addressed to R.A. (email: rabe@rs.noda.tus.ac.jp).
} 
T he Kit proto-oncogene encodes a type III receptor tyrosine kinase (RTK), a class of proteins that includes plateletderived growth factor receptors (PDGFR), Fms, and Fmslike tyrosine kinase 3 (Flt3) ${ }^{1-3}$. Kit is expressed on mast cells, interstitial cells of Cajal, haematopoietic cells, germ cells and melanocytes ${ }^{4}$. On stimulation with stem cell factor (SCF), Kit triggers many signalling events at the plasma membrane (PM), resulting in cell proliferation, survival and differentiation ${ }^{5}$.

Kit is composed of five $\mathrm{N}$-glycosylated immunoglobulin domains in the N-terminal extracellular portion that bind SCF, as well as a transmembrane domain, and an intracellular C-terminal tyrosine kinase domain ${ }^{6}$. The binding of SCF autophosphorylates Kit on specific tyrosine residues. Kit then binds to other cytoplasmic enzymes containing Src hohomogy-2 (SH2) domain, and this complex phosphorylates other proteins $^{3-6}$. This process activates the phosphatidylinositol 3-kinase-Akt (PI3K-Akt) pathway, the Ras-Raf-Erk cascade and Src kinases, which regulate cell growth, gene expression and cytoskeletal structures ${ }^{7-10}$.

In many mast cell neoplasms and gastrointestinal stromal tumours, Kit has gain-of-function mutations, causing permanent, ligand-independent activation of the receptor ${ }^{11-14}$. In human neoplastic mast cell disorders such as mastocytosis and mast cell leukemia, Kit often has an Asp816Val substitution (D816V) in the kinase domain ${ }^{12,13}$. Similar mutations are also found in rat mast cell leukemia (RBL-2H3; D817Y) and a mouse mastocytoma $(\mathrm{P} 815 ; \mathrm{D} 814 \mathrm{Y})^{13}$. Their permanent activation of the PI3K-Akt pathway causes neoplastic transformation. When mutant Kit activates the PI3K-Akt pathway, this suppresses apoptotic proteins such as Bim, resulting in cell survival ${ }^{15-18}$. When mutant Kit phosphorylates signal transduction and activator of transcription (STAT) proteins, they move from the cytoplasm to the nucleus and cause transcription of protooncogenes such as $c-m y c^{19-21}$.

Cancer-causing mutants of RTKs, such as $\operatorname{Met}(\mathrm{D} 1246 \mathrm{~N})$ and Flt3-internal tandem duplication (Flt3-ITD), can cause incorrect signalling not just from the PM, but also from intracellular compartments, because their activated kinase domain is always exposed $^{22-26}$. These mutations also change the trafficking and degradation of the receptors, because they change glycosylation and ubiquitination, and receptors accumulate in the wrong compartments ${ }^{22-27}$. Signalling by oncogenic RTKs on intracellular compartments has been implicated in their transforming ability, but the mechanism of signalling by mutant Kit is not fully understood.

We recently established two mast cell lines, RCM and R, from mouse splenocytes. RCM cells proliferate without cytokines, generate tumours in vivo and express a mutant Kit, Kit(D814Y). $\mathrm{R}$ cells require cytokines to proliferate and express wild-type Kit $(\mathrm{Kit}(\mathrm{wt}))$. This scenario allows us to compare $\mathrm{Kit}(\mathrm{wt})$ with $\mathrm{Kit}(\mathrm{D} 814 \mathrm{Y})$ in an identical cellular background.

To explore how Kit(D814Y) transduces oncogenic signals, we studied what pathways it activates, from various subcellular compartments, using immunofluorescence confocal microscopy, vesicle immunoprecipitation and chemical inhibition of intracellular trafficking.

In mice cells, Kit(D814Y) from the PM accumulates on endolysosomes through clathrin-mediated endocytosis (CME); this occurs in a kinase activity-dependent manner. It then forms a complex with PI3K, and activates Akt, leading to cell proliferation. Also, soon after Kit(D814Y) is synthesized, it appears in the endoplasmic reticulum (ER), where it causes oncogenic activation of STAT5. Two other mast cell lines, HMC-1 and RBL-2H3, from humans and rats, gave similar results. Our findings demonstrate that Kit signalling from subcellular compartments is necessary for the neoplastic proliferation of mast cells.

\section{Results}

$\mathrm{Kit}^{\mathrm{D} 814 \mathrm{Y}}$ causes autonomous proliferation of mouse RCM cells. We recently established two mast cell lines from mouse splenocytes, RCM cells and R cells, bearing c-Kit and FceRI. RCM cells grow without cytokines and develop tumours in vivo (Fig. 1a). These cells show constitutively tyrosine-phosphorylated 145- and $160-\mathrm{kDa}$ proteins, identified as the Kit tyrosine kinase (Fig. 1b,c; see also Fig. 4b). Furthermore, Kit's kinase domain has an Asp814Tyr (D814Y) mutation (Fig. 1d), which keeps the kinase permanently active ${ }^{12,13,21}$.

Immunoprecipitation assays confirmed that $\mathrm{Kit}(\mathrm{wt})$ in $\mathrm{R}$ cells and pt18 cells $^{28}$ was activated in a ligand-dependent manner, whereas Kit(D814Y) was phosphorylated and associated with the PI3K p85 subunit without SCF (Fig. 1e; see also Fig. 3i), and thus was permanently active. Glutathione $S$-transferase-pulldown (GST-pulldown) assays showed that the C-terminal or N-terminal SH2 domains of $\mathrm{p} 85$ (SH2c or $\mathrm{SH} 2 \mathrm{n})$ were associated with SCF-stimulated $\mathrm{Kit}(\mathrm{wt})$ and $\operatorname{Kit}(\mathrm{D} 814 \mathrm{Y})$ (Fig. 1f). Next, we treated RCM cells with PKC412, an inhibitor of Kit tyrosine kinase ${ }^{29}$. Similar to previous reports ${ }^{16,29}$, PKC412 inhibited the phosphorylation of $\mathrm{Kit}(\mathrm{D} 814 \mathrm{Y})$ and p85's association with $\operatorname{Kit}(\mathrm{D} 814 \mathrm{Y})$, and also inhibited cell proliferation in a dose-dependent manner (Fig. 1f,g and Supplementary Fig. 1; see also Fig. 4c). We next performed RNA interference experiments to suppress Kit(D814Y). Western blotting showed $80-85 \%$ less $\operatorname{Kit}(\mathrm{D} 814 \mathrm{Y})$ protein after transfection with Kit1 and Kit2 small interfering RNAs (siRNAs) for $20 \mathrm{~h}$ (Fig. 1h, left). Knockdown of Kit(D814Y) also suppressed cell proliferation (Fig. 1h, right). Thus, the kinase activity is required for autonomous proliferation.

$\mathrm{Kit}^{\mathrm{D} 814 \mathrm{Y}}$ localizes to endolysosomes. Kit mutants exogenously expressed in CHO, NIH3T3 or HEK293 cells are found mainly in the Golgi apparatus or ER in an immaturely glycosylated form ${ }^{30-32}$. To investigate Kit's glycosylation state, we treated Kit(D814Y) from RCM cells with endoglycosidase $\mathrm{H}$, which digests immature high-mannose forms, but not mature complex-glycosylated forms. Figure $2 \mathrm{a}$ shows that most $\operatorname{Kit}(\mathrm{D} 814 \mathrm{Y})$, like Kit(wt), was present in a complex-glycosylated form. Kit(wt) and Kit(D814Y) both shifted to a non-glycosylated form following the complete digestion of $\mathrm{N}$-linked glycans by peptide- $\mathrm{N}$-glycosidase $\mathrm{F}$.

Next, we investigated the subcellular localization of Kit in paraformaldehyde-fixed (PFA-fixed) cells by immunofluorescence confocal microscopy. Consistent with previous reports 933,34 , in pt18 and R cells, most Kit(wt) was at the PM, whereas in RCM cells Kit(D814Y) was mainly on vesicular structures (Fig. 2b). We investigated these structures and calculated Pearson's correlation coefficients (Pearson's R) between Kit and various markers: calnexin (ER), TGN46 (Golgi), EEA1, CD63 (endosome), LAMP1 and cathepsin D (endolysosome). As cathepsin D and CD63 could not be detected by immunofluorescence in PFA-fixed cells, we fixed RCM cells with methanol to visualize those proteins. Although Kit's distributions were largely similar between the different methods (Supplementary Fig. 2a,b), methanol caused fluorescence loss in the cytosol and nucleus (compare Fig. 2c with 2d). Kit(D814Y) co-localized with LAMP1 significantly, and with cathepsin D-positive vesicles somewhat, suggesting it is mainly present on endolysosomes (Fig. $2 \mathrm{c}, \mathrm{d}, \mathrm{g})$. Moreover, green fluorescent protein-tagged (GFP-tagged) Kit(D814Y) was colocalized with LAMP1, and with fluorescent dextran, which is incorporated into endocytic compartments ${ }^{35}$ (Fig. 2e). Kit(D814Y) surrounded cathepsin D as well as dextran (Fig. 2d,e, magnified images), indicating that the kinase domain is exposed on the cytoplasmic surface of endolysosomes. 


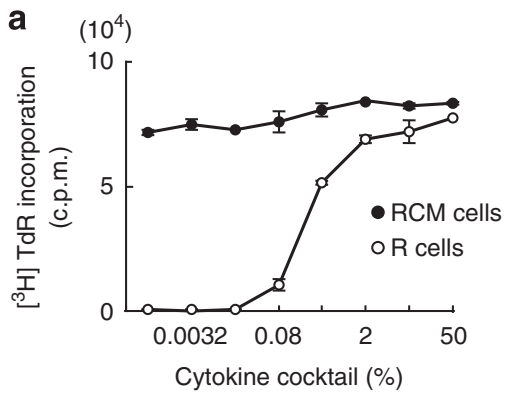

pt18 cells

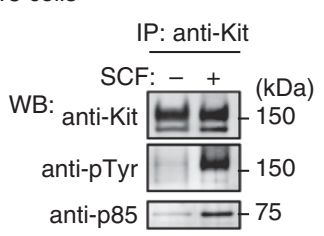

IP: anti-Kit

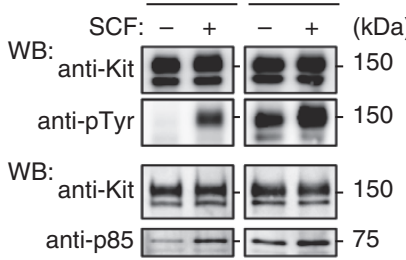

b

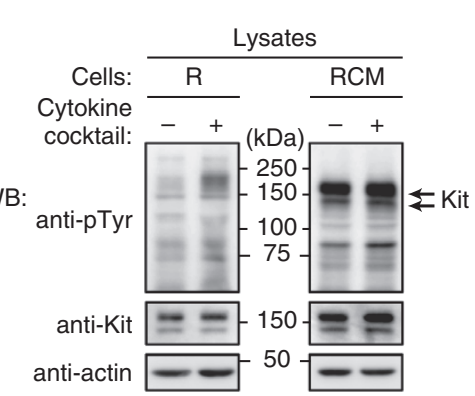

f

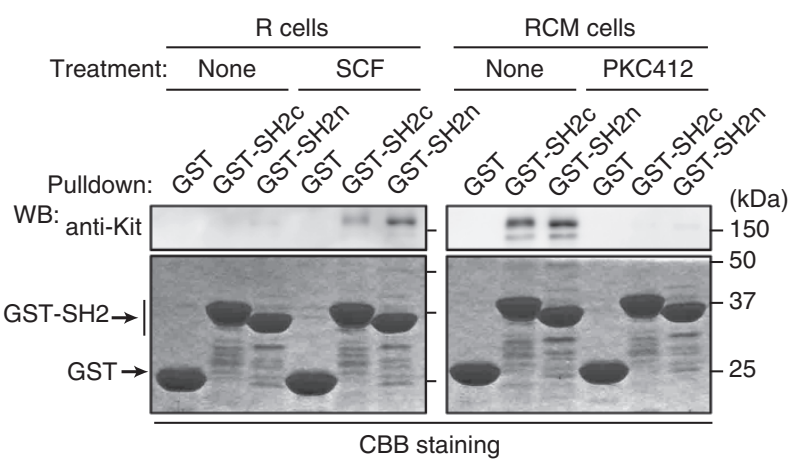

C

Lysates from starved cells

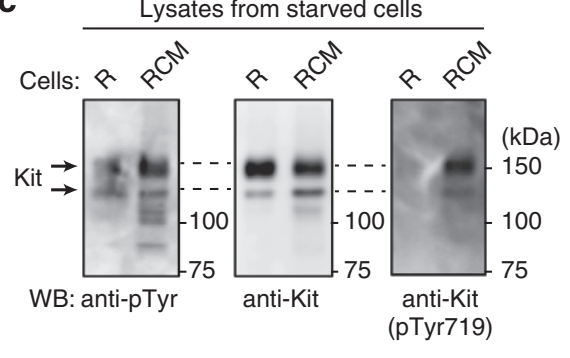

g
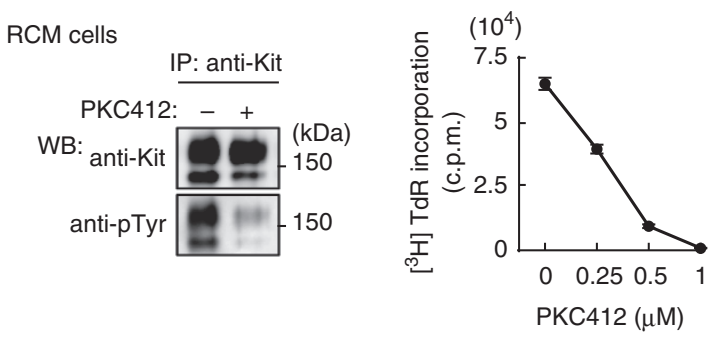

h
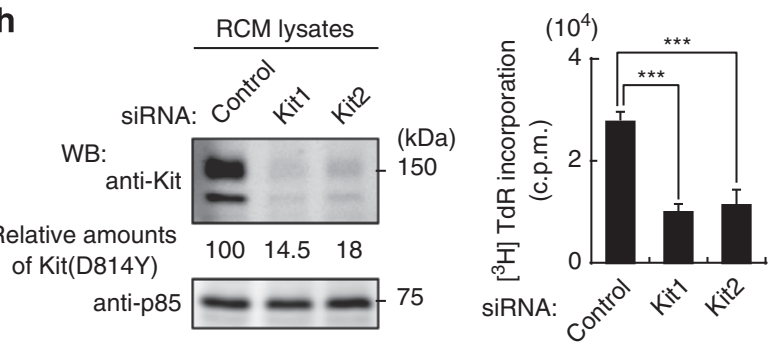

Figure 1 | Kit(D814Y) is essential for autonomous proliferation of mouse RCM cells. (a) RCM and R cells were cultured in the indicated cytokine cocktail for $48 \mathrm{~h}$. Proliferation was assessed by $\left[{ }^{3} \mathrm{H}\right.$ ]-thymidine incorporation into R (open circles) and RCM cells (filled circles). Results (c.p.m.) are means \pm s.d. $(n=3)$. NB: RCM cells proliferated without the cytokine cocktail. $(\mathbf{b}, \mathbf{c})$ Expression of constitutively phosphorylated Kit in RCM cells. Starved R and RCM cells were treated with the cytokine cocktail for $5 \mathrm{~min}$. Lysates were immunoblotted with anti-phosphotyrosine (anti-pTyr), anti-Kit, anti-Kit(pTyr719) and anti-actin. Arrows indicate constitutively tyrosine-phosphorylated protein corresponding to Kit in RCM cells. (d) Schematic representations of normal Kit and Kit(D814Y) showing the extracellular domain (ECD), the transmembrane domain (TM), the kinase domain, Asp814 in the kinase domain (D in black) and the tyrosine mutation at 814 ( $\mathrm{Y}$ in red). (e) Constitutive activation of Kit(D814Y). Starved pt18, R, and RCM cells were treated with 50 ng ml ${ }^{-1}$ SCF for $5 \mathrm{~min}$. Kit was immunoprecipitated then immunoblotted. (f) GST-pulldown. RCM or R cells were treated with $1 \mu \mathrm{M}$ PKC 412 (Kit kinase inhibitor) for $24 \mathrm{~h}$ or $50 \mathrm{ng} \mathrm{ml}^{-1} \mathrm{SCF}$ for $5 \mathrm{~min}$, respectively. Kit was pulled down with GST-SH2c or GST-SH2n, and amounts of Kit pulled down was assayed by immunoblotting. GST proteins were visualized by Coomassie staining. (g) Effect of PKC412 on the kinase activity of Kit(D814Y). RCM cells treated with $1 \mu M$ PKC 412 were cultured for $24 \mathrm{~h}$. Anti-Kit immunoprecipitates were immunoblotted. The graph shows the levels of $\left[{ }^{3} \mathrm{H}\right]$-thymidine incorporation into RCM cells at the indicated PKC412 concentrations. Results (c.p.m.) are means \pm s.d. $(n=3)$. (h) RCM cells were transfected with control siRNA or Kit siRNAs (Kit1 or Kit2) and cultured for $20 \mathrm{~h}$. Lysates were immunoblotted with anti-Kit and anti-p85. Amounts of Kit(D814Y) are expressed relative to control cell lysate, after normalization with p85. The graph shows the levels of $\left[{ }^{3} \mathrm{H}\right]$-thymidine incorporation into RCM cells. Results (c.p.m.) are means \pm s.d. $(n=3)$. Data were subjected to one-way ANOVA with Dunnett's multiple comparison post-hoc test. ${ }^{\star \star \star} P<0.001$.

Next, we compared the distribution of $\operatorname{Kit}(\mathrm{D} 814 \mathrm{Y})$ and recycling endosomes using cholera toxin subunit B (CTXB; a recycling endosome marker) ${ }^{36}$. Kit's localization to recycling endosomes was significantly less than that to endolysosomes
(Fig. 2f,g), and a second marker of recycling endosomes, Rab11, confirmed this (Supplementary Fig. 2c). These results indicate that Kit(D814Y) traffics to endolysosomes rather than recycling to the PM. 
$\mathrm{Kit}^{\mathrm{D} 814 \mathrm{Y}}$ moves to endolysosomes by kinase-mediated endocytosis. In RCM cells treated for $24 \mathrm{~h}$ with the kinase inhibitor $\mathrm{PKC} 412$, there was more $\operatorname{Kit}(\mathrm{D} 814 \mathrm{Y})$ at the PM and less in endolysosomes (Fig. 3a). Treatment did not cause accumulation of $\mathrm{Kit}(\mathrm{D} 814 \mathrm{Y})$ on either ER or Golgi. Following removal of inhibitor, Kit(D814Y) moved within $60 \mathrm{~min}$ from the PM, via endosomes, to endolysosomes (Supplementary Fig. 3a). These results suggest that Kit's kinase activity is needed for endocytosis, but not for biosynthetic traffic to the PM. Figure $3 \mathrm{~b}$ shows that 24-h treatment with an inhibitor of lysosomal proteases $\left(\mathrm{NH}_{4} \mathrm{Cl}\right)$ resulted in retention of Kit(D814Y) inside RCM cells, indicating that endocytosed $\mathrm{Kit}(\mathrm{D} 814 \mathrm{Y})$ is targeted to lysosomes, and subsequently degraded. In the presence of cycloheximide, an inhibitor of protein synthesis, Kit(D814Y) was degraded within $5 \mathrm{~h}$, whereas transferrin receptor (TfR), which undergoes recycling, was unchanged (Fig. 3c), suggesting that Kit traffics constitutively to lysosomes.

In endocytosis of growth factor receptors, for example, of epidermal growth factor (EGF) and transforming growth factor $\beta$ (TGF $\beta$ ), clathrin plays a critical role in their stability ${ }^{37,38}$. Accordingly, receptor-mediated endocytosis is divided into two major categories: non-clathrin endocytosis (NCE) and $\mathrm{CME}^{37-39}$. To study the role of clathrin in $\operatorname{Kit}(\mathrm{D} 814 \mathrm{Y})$ endocytosis, we treated RCM cells with hypertonic sucrose, thereby blocking the formation of clathrin-coated pits ${ }^{40}$. Within $3 \mathrm{~h}$, this reduced the protein levels of mature Kit(D814Y) and TfR without affecting the cytosolic protein p85 (Fig. 3d,e). Similar results were obtained from RCM cells treated with pitstop2, a selective inhibitor of $\mathrm{CME}^{41}$ (Fig. 3f). To confirm that, with CME blocked, Kit and TfR were being processed by NCE, we treated cells for $3 \mathrm{~h}$ with pitstop 2 plus filipin, or with sucrose plus filipin, which blocks NCE by disrupting lipid rafts ${ }^{37,42}$. Kit(D814Y) and TfR were then found at the PM, presumably protected from rapid degradation (Fig. 3g,h and Supplementary Fig. 3b). In cells treated with filipin alone, the protein levels and localization of Kit(D814Y) were unaffected (Fig. 3g,h and Supplementary Fig. 3b,c). Similar to sucrose and pitstop 2 , knockdown of the assembly polypeptide- $2 \alpha$ subunit $(\mathrm{AP} 2 \alpha)$, which is required for $\mathrm{CME}^{39}$, decreased the protein levels of Kit(D814Y) and TfR (Supplementary Fig. 3d). Thus, the major pathway for Kit(D814Y) endocytosis is CME.

In NCE, ubiquitination of receptors and other endocytic cargo is important for association with the ESCRT (endosomal sorting complexes required for transport) machinery, for rapid incorporation into lysosomes and for degradation ${ }^{39,43-45}$. As Kit(D814Y) mainly undergoes CME not NCE, we hypothesized that it may not be fully ubiquitinated. When Kit(wt) was stimulated with SCF, in pt18 and R cells it became fully ubiquitinated, and was degraded within $30 \mathrm{~min}$ (Figs $3 \mathrm{i}$ and $6 \mathrm{~g}$; see also Fig. 31), consistent with previous reports ${ }^{31-34,45}$. In sharp contrast, in RCM cells ubiquitination of $\operatorname{Kit}(\mathrm{D} 814 \mathrm{Y})$ was much lower, regardless of the presence or absence of SCF. When CME was blocked, Kit(D814Y) became substantially ubiquitinated (Fig. 3j), presumably as it then trafficked via NCE. These results suggest that, in RCM cells, most Kit(D814Y) undergoes CME depending on its kinase activity, and accumulates on the cytoplasmic surface of endolysosomes, but not in a fully ubiquitinated state. In support of this, degradation of $\mathrm{Kit}(\mathrm{D} 814 \mathrm{Y})$ was significantly slower than that of activated Kit(wt) in the presence of cycloheximide (Fig. 3k).

Next, to investigate the mechanism of endosome-to-lysosome trafficking of Kit, we knocked down tumour-susceptibility gene 101 (Tsg101), a component of ESCRT ${ }^{43,44,46}$. Figure 31 shows that in $\mathrm{R}$ cells treated with SCF for $30 \mathrm{~min}$, Tsg101 knockdown inhibited the degradation of Kit(wt) but not of TfR (see also Supplementary Fig. 5e). These results suggest that Kit(wt) is incorporated into lysosomes in a manner that is dependent on ESCRT, similar to EGFR ${ }^{39,43,46}$. By contrast, knockdown decreased Kit(D814Y) in RCM cells (Fig. 3m). As ESCRT depletion enhances ESCRT-independent transport into lysosomes ${ }^{46}$, our results indicate that $\mathrm{Kit}(\mathrm{D} 814 \mathrm{Y})$ is incorporated into lysosomes in a manner that is independent of ESCRT.

Activation of Akt and STAT5 is necessary for proliferation of RCM cells. Neoplastic transformation of mast cells involves phosphorylation and activation of Akt, STAT proteins, Erk1/2 and JAKs ${ }^{4,13,15-21}$. In RCM cells, Akt and STAT5, but not Erk1/2, STAT3 and JAK2, were constitutively phosphorylated (Supplementary Fig. 4a,b).

To investigate whether it was Kit(D814Y) that had activated Akt and STAT5, we inhibited Kit(D814Y) by PKC412 or siRNAmediated knockdown. Both treatments inhibited the activation of Akt and STAT5 (Fig. 4a,b). We further found that the PI3K p85 subunit was co-immunoprecipitated with $\operatorname{Kit}(\mathrm{D} 814 \mathrm{Y})$, and that PKC412 blocked this association (Fig. 4c; see also Fig. 1f, right). In this cell line, a PI3K inhibitor LY294002 suppressed Akt activation in a dose-dependent manner (Fig. 4d), as reported previously $7,19,47$. Thus, Kit(D814Y) activates Akt through association with PI3K.

Next, we tested whether Akt activation was required for autonomous proliferation. In RCM cells, the inhibitor Akti repressed the activation of Akt without affecting STAT5. It also caused a dose-dependent suppression of cell proliferation (Fig. 4e). Although the PI3K-Akt pathway has a role in RTK trafficking $35,48,49$, no redistribution was seen here on treatment with either LY294002 or Akti (Fig. 4f). This shows that the PI3K-

\footnotetext{
Figure 2 | Kit(D814Y) localizes to endolysosomes in mouse RCM cells. (a) Glycosylation of Kit(D814Y). Lysates from pt18, R and RCM cells were treated with peptide $\mathrm{N}$-glycosidase $\mathrm{F}$ (PNGase F) or endoglycosidase $\mathrm{H}$ (endo $\mathrm{H}$ ), then immunoblotted with anti-Kit. CG, complex-glycosylated form; DG, deglycosylated form; HM, high mannose form. NB: most Kit(D814Y) was a mature complex-glycosylated form. (b) Localization of normal Kit and Kit(D814Y). RCM, R or pt18 cells were fixed with PFA and stained with anti-Kit. Phase contrast images are shown. Bars, $10 \mu \mathrm{m}$. NB: normal Kit accumulated at the PM; Kit(D814Y) at vesicular structures. (c-g) Localization of Kit(D814Y) to endolysosomes. (c) PFA-fixed or (d) methanol-fixed RCM cells were double-stained with anti-Kit (green) in conjunction with the indicated antibody (red). Insets show the magnified images of the boxed area. Representative images of Kit-positive endolysosomes containing cathepsin D are shown. Bars, $5 \mu \mathrm{m}$. CD63, cluster of differentiation 63; EEA1, early endosome antigen-1; LAMP1, lysosome-associated membrane protein-1; TGN46, trans-Golgi network 46. (e) Endolysosomal localization of Kit(D814Y)-GFP. RCM cells transfected with Kit(D814Y)-GFP. (Upper panels) Cells were stained with anti-LAMP1 (endolysosome marker; red). (Lower panels) For visualizing endocytic compartments, cells were incubated with $1 \mathrm{mg} \mathrm{ml}^{-1}$ AF647-dextran for $1 \mathrm{~h}$. Expressed protein and dextran were visualized by GFP (green) and AF647 fluorescence (blue). Magnified images of the boxed area are shown. Arrowheads indicate Kit-positive endolysosomes that contain dextran. Bars, $5 \mu \mathrm{m}$. NB: Kit(D814Y) surrounded cathepsin D and dextran. (f) For visualizing recycling endosomes, RCM cells were incubated for $1 \mathrm{~h}$ with $5 \mu \mathrm{g} \mathrm{ml}^{-1}$ AF647-cholera toxin subunit B (AF647-CTXB) and stained with anti-Kit (green). The toxin was visualized with AF647 fluorescence (blue). Magnified images of the boxed area are shown. Bar, $5 \mu \mathrm{m}$. (g) Pearson's coefficients (Pearson's R) were calculated by intensity correlation analysis of Kit(D814Y) versus organelle markers. Results are means \pm s.d. $(n=10 \sim 20)$. Data were subjected to one-way ANOVA with Dunnett's multiple comparison post-hoc test. ${ }^{\star \star \star} P<0.001$.
} 
Akt pathway has an essential role in cell proliferation but does not influence Kit(D814Y) trafficking.

We next suppressed STAT5 function by utilizing STAT5 inhibitor (STAT5i) or knockdown. Both treatments inhibited the proliferation of RCM cells (Fig. 4g,h). Knockdown had no effect

a

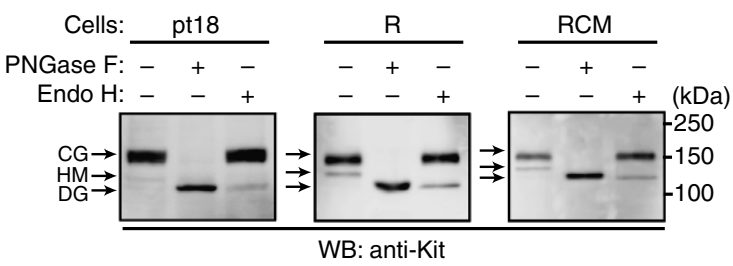

b

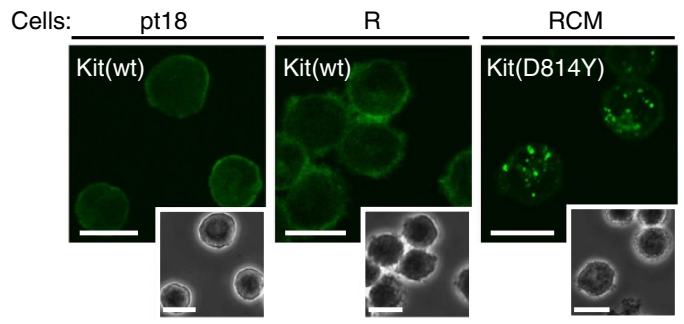

C RCM cells (PFA fixation)
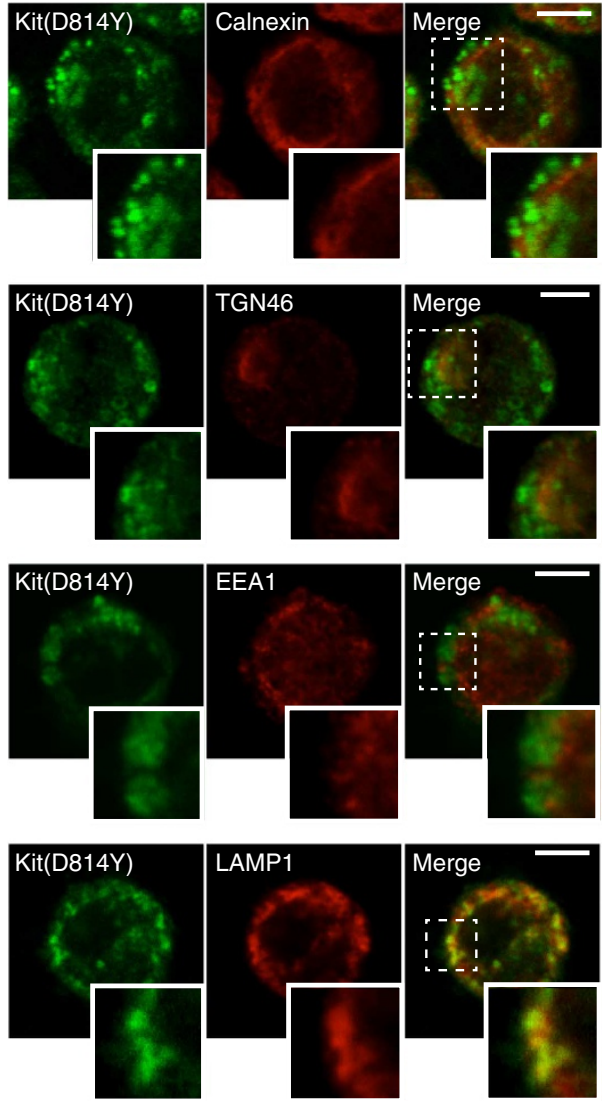

on the activation of Akt. On the contrary, proliferation was unaffected by Erk1/2 inhibition with U0126 (Supplementary Fig. 4c). Taken together, these results suggest that Kit(D814Y) constitutively activates the PI3K-Akt pathway and STAT5, and that these activations are essential for autonomous proliferation.

d RCM cells (methanol fixation)

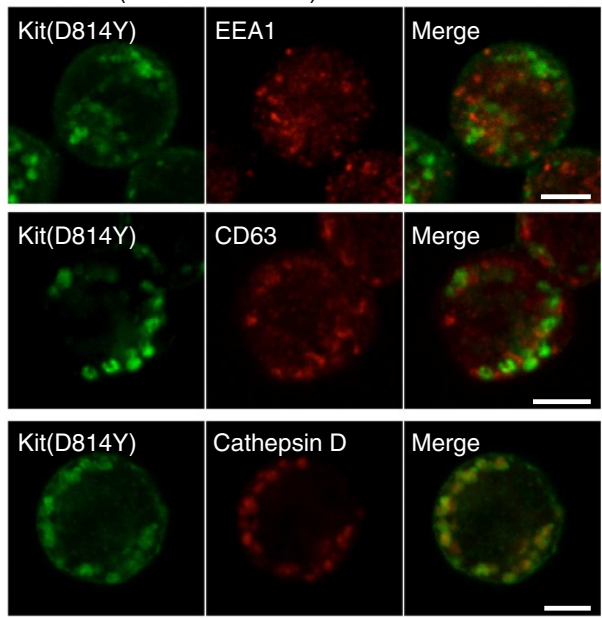

Magnified images of endolysosomal region

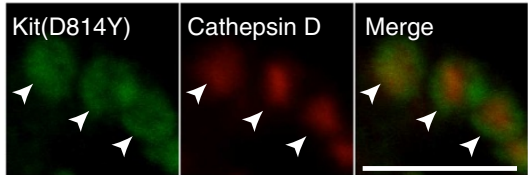

e RCM cells transfected with Kit(D814Y)-GFP

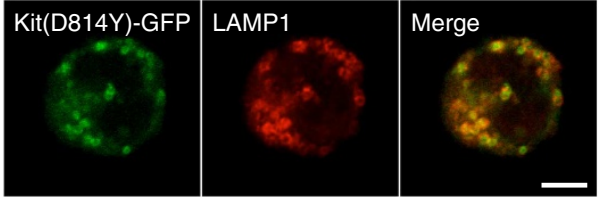

Incubation with dextran

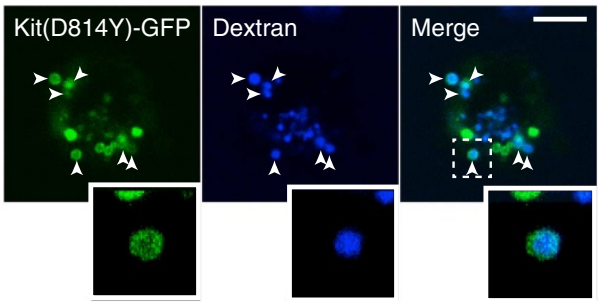

f RCM cells treated with CTXB (PFA fixation)

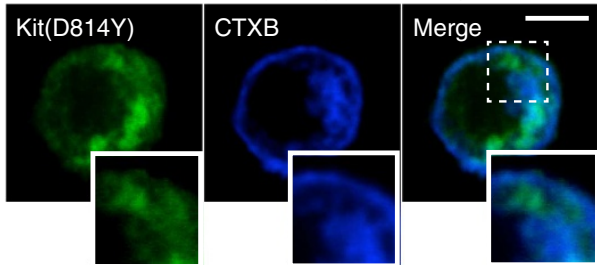

g
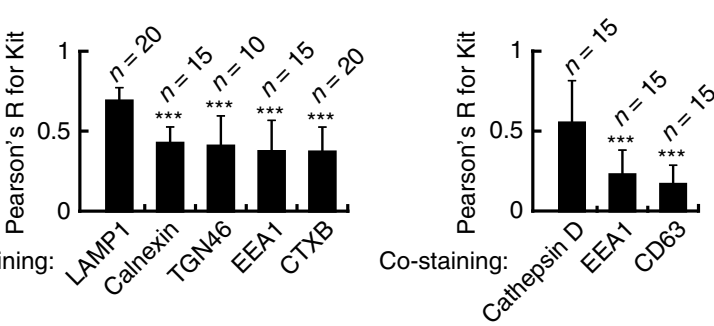
$\mathrm{Kit}^{\mathrm{D} 814 \mathrm{Y}}$ activates Akt through PI3K only on endolysosomes. Activated RTKs, such as EGFR, Met, and PDGFR can transduce signals not only on the cell's outer membrane, but also on endocytic compartments ${ }^{23,24,49-52}$. To examine whether endolysosomes serve as a platform for oncogenic Kit signalling, we purified endolysosomes from RCM cells by immunoprecipitation, using an anti-LAMP1 antibody. Figure 5a shows that Kit(D814Y), Akt and p85, but not STAT5, were found in the endolysosomal fraction. As active Akt is bound to phosphatidylinositol-3,4,5-triphosphate $\left(\mathrm{PI}(3,4,5) \mathrm{P}_{3}\right)$, which is generated by $\mathrm{PI} 3 \mathrm{~K}$, through its pleckstrin homology $(\mathrm{PH})$ domain $^{3,53}$, it is likely that Akt and Kit(D814Y)-PI3K become associated in endolysosomes. To test this hypothesis, we investigated whether $\mathrm{PI}(3,4,5) \mathrm{P}_{3}$ was generated on endolysosomes, by expression of a GFP-tagged Akt PH domain $(\mathrm{PH}-\mathrm{GFP})^{54}$. In RCM cells most PH-GFP was on vesicles but not at the PM, whereas $\mathrm{PH}(\mathrm{R} 25 \mathrm{C})$-GFP, a non- $\mathrm{PI}(3,4,5) \mathrm{P}_{3}$-binding mutant, was in the cytoplasm (Fig. 5b). As PH-GFP could not be detected after immunofluorescence, we directly visualized endocytic compartments by fluorescent dextran. Figure $5 \mathrm{c}$ shows that they were significantly co-localized with PH-GFP. Furthermore, phosphorylated Akt was found on vesicles where Kit localized (Fig. 5d). These results suggest that Akt is activated by Kit(D814Y) predominantly on endolysosomes.

Next, we investigated whether $\operatorname{Kit}(\mathrm{D} 814 \mathrm{Y})$ must localize to endolysosomes to activate Akt. We used bafilomycin A1 (BafA1), which blocks endosomal trafficking without affecting internalization and recycling 44,55 . After $24 \mathrm{~h}$, Kit(D814Y) was rare in endolysosomes (LAMP1-positive), but common in endosomes (EEA1-positive) (Fig. 5e and Supplementary Fig. 5a), indicating that trafficking from endosomes to endolysosomes is blocked. Figure $5 \mathrm{f}$ shows that BafA1 treatment also prevented Kit(D814Y) degradation. BafAl did not affect Kit(D814Y)'s kinase activity (Fig. 5f, left). It reduced activation of Akt but not of STAT5 (Fig. 5f). BafAl did not suppress the association of Kit(D814Y) with p85 and did not affect Kit phosphorylation at Tyr719 (Fig. 5f, left and Supplementary Fig. 5b), a binding site for p85 (refs 7,8,53). Therefore, Kit(D814Y) presumably associates with PI3K before reaching endolysosomes. Treatment with $\mathrm{NH}_{4} \mathrm{Cl}$, (inhibits lysosomal proteases) for $24 \mathrm{~h}$ preserved $\mathrm{Kit}(\mathrm{D} 814 \mathrm{Y})$ from degradation, but did not affect its localization to endolysosomes (Fig. 5e, bottom). In contrast to BafAl, $\mathrm{NH}_{4} \mathrm{Cl}$ had no effect on the activation of Akt (Fig. 5f, right), suggesting that Kit must localize to endolysosomes to activate Akt. In support of this conclusion, when Kit(D814Y) trafficking to endolysosomes was blocked by BafA1, p85 and Akt did not co-fractionate with the endolysosomal membrane (Supplementary Fig. 5c).

To examine whether the inhibition of Akt by BafAl resulted from apoptosis, we performed immunoblotting for cleaved caspase-3, an apoptosis marker ${ }^{20}$. Figure $5 \mathrm{~g}$ shows that BafA1 treatment for $24 \mathrm{~h}$ induced cleavage of caspase-3, but treatment for $3 \mathrm{~h}$ did not. The treatment for $3 \mathrm{~h}$ also inhibited Akt (Fig. 5g), indicating that the effect of BafAl on Akt activity resulted from inhibition of Kit trafficking, but not from apoptosis.

$\mathrm{Kit}(\mathrm{wt})$ is also transported through the endocytic pathway after SCF binding ${ }^{33,34}$. To examine whether Kit(wt) also activated a PI3K-Akt pathway on endolysosomes, we treated $\mathrm{R}$ cells with BafAl for $3 \mathrm{~h}$ and then stimulated them with SCF. Akt remained active up to $60 \mathrm{~min}$ after SCF stimulation, regardless of the presence or absence of BafA1 (Fig. 5h). Similar results were obtained from pt 18 cells (Supplementary Fig. 5d). Figure 5i shows that in R cells stimulated with SCF for 30 min, p85 and Akt were absent from endolysosomes. Furthermore, in SCF-stimulated R cells, phosphorylated Akt and PH-GFP were not detected in endolysosomal vesicles (Fig. 5j,k). Also, accumulation of Kit(wt) on endosomes following Tsg101 knockdown did not activate Akt (Supplementary Fig. 5e), suggesting that Kit(wt) activates the PI3K-Akt pathway transiently, presumably when bound to the PM. However, we could not exclude the possibility that Kit(wt) activates Akt soon after endocytosis.

Partially glycosylated $\mathrm{Kit}^{\mathrm{D} 814 \mathrm{Y}}$ on the ER activates STAT5. Cytochalasin D, an inhibitor of endocytosis through actin depolymerization 35,36 , prevented the activation of Akt without influencing Kit(D814Y)'s kinase activity and p85's association with Kit(D814Y), but the treatment did not affect STAT5 activity (Supplementary Fig. 5b,f). These results suggest that Kit(D814Y) activates STAT5 from a different subcellular compartment. Thus, we determined where in the cell $\operatorname{Kit}(\mathrm{D} 814 \mathrm{Y})$ activates STAT5. First, we examined whether exocytic transport of Kit(D814Y) from the Golgi apparatus towards the PM was required. We treated RCM cells with monensin, which inhibits export from the Golgi by blocking intra-Golgi transport ${ }^{56}$. After 24-h treatment, Kit(D814Y) co-localized with the Golgi marker GM130 (Fig. 6a). Figure $6 \mathrm{~b}$ shows that monensin treatment resulted in expression of partially glycosylated Kit(D814Y). Monensin had no effect on the autophosphorylation of Kit(D814Y), or on p85's association with Kit(D814Y) (Fig. 6b, left and Supplementary Fig. 5b). Moreover, monensin abolished Akt activation, presumably because Kit could no longer locate to endolysosomes. STAT5 activation was not affected (Fig. 6b, right), suggesting that Kit activates STAT5 on the Golgi and/or ER, not at the PM.

Next, we used tunicamycin to inhibit ER export of Kit(D814Y) by blocking protein glycosylation ${ }^{26,57}$. Tunicamycin suppressed trafficking from ER to Golgi, and Kit(D814Y) accumulated on the ER (Fig. 6c, middle panels). Tunicamycin-treated cells also expressed non-glycosylated Kit(D814Y) (Fig. 6d, top). Like monensin, tunicamycin did not stop the autophosphorylation of $\mathrm{Kit}(\mathrm{D} 814 \mathrm{Y})$ or p85's association with $\mathrm{Kit}(\mathrm{D} 814 \mathrm{Y})$, but did

\footnotetext{
Figure 3 | Kit(D814Y) traffics from the plasma membrane to endolysosomes through its kinase activity and clathrin-mediated endocytosis. (a) RCM cells cultured in the presence of $1 \mu \mathrm{M}$ PKC 412 (Kit inhibitor) for $24 \mathrm{~h}$ and stained with anti-Kit (green) and anti-calnexin (ER marker; red). Bars, $10 \mu \mathrm{m}$. The graph shows the percentage of cells with predominant PM localization of Kit(D814Y). Results (\%) represent means \pm s.d. from three independent experiments $\left(n>200\right.$ cells). ${ }^{\star \star \star} P<0.001$, Student's $t$-test. $(\mathbf{b}, \mathbf{c}) \mathrm{RCM}$ cells were cultured in the presence of $(\mathbf{b}) 20 \mathrm{mM} \mathrm{NH}_{4} \mathrm{Cl}$ (inhibits lysosomal proteases) for $24 \mathrm{~h}$ or (c) $200 \mu \mathrm{g} \mathrm{ml}^{-1}$ cycloheximide (inhibits protein synthesis) for the indicated periods, then immunoblotted. Total protein levels were confirmed by Coomassie staining. (d-f) Inhibition of clathrin-mediated endocytosis by sucrose or pitstop2. RCM cells were treated with (d,e) $0.45 \mathrm{M}$ sucrose or (f) $50 \mu \mathrm{M}$ pitstop2. After $3 \mathrm{~h}$, cells were stained with antibody. Bars, $10 \mu \mathrm{m}$. (f) Immunoblots. (g,h) Inhibition of non-clathrin endocytosis by filipin. RCM cells treated with $1 \mu \mathrm{g} \mathrm{ml}{ }^{-1}$ filipin and/or $50 \mu \mathrm{M}$ pitstop2 were cultured for $3 \mathrm{~h}$. (g) Lysates were immunoblotted. Total protein levels were confirmed by Coomassie staining. (h) Cells were stained with anti-Kit (cyan) and anti-TfR (red). Bars, $5 \mu$ m. (i,j) Ubiquitination of Kit(D814Y). Starved pt18, $\mathrm{R}$ and RCM cells were treated with $50 \mathrm{ng} \mathrm{ml}^{-1} \mathrm{SCF}$ (i) or $0.45 \mathrm{M}$ sucrose (j) for $5 \mathrm{~min}$. Anti-Kit immunoprecipitates were immunoblotted. Ub: ubiquitin. (k) RCM or SCF-treated R cells were cultured in $200 \mu \mathrm{g} \mathrm{ml}{ }^{-1}$ cycloheximide (CHX) for the indicated periods, then immunoblotted. The graph shows the percentage of mature Kit remaining after $\mathrm{CHX}$ treatment. Results (\%) represent means \pm s.d. from three independent experiments. ${ }^{\star} P<0.05$; ${ }^{\star \star} P<0.01$, Student's $t$-test. (I, $\left.\mathbf{m}\right) \mathrm{R}$ cells or RCM cells were transfected with Tsg101 siRNAs (Tsg1 or Tsg2) and cultured for $24 \mathrm{~h}$. Lystes from R cells treated with $50 \mathrm{ng} \mathrm{ml}^{-1} \mathrm{SCF}$ for $30 \mathrm{~min}$ (I) or RCM cells (m) were immunoblotted.
} 
prevent Akt activation (Fig. 6d, top and Supplementary Fig. 5b). STAT5 activation was again enhanced (Fig. 6d, right), indicating that Kit(D814Y) activates STAT5 on the ER.

Brefeldin A (BFA) also inhibits protein export from the $\mathrm{ER}^{26,30,58}$. On 16-h BFA treatment, as with tunicamycin, partially glycosylated Kit(D814Y) accumulated on the ER and STAT5 became active (Fig. 6c,d). STAT5 was seen in the nucleus and on cytosolic reticular structures, but not at the PM (Fig. 6e, top). BFA treatment significantly enhanced the co-localization of Kit(D814Y) with STAT5 on the reticular structures (Fig. 6e, bottom), further suggesting that Kit(D814Y) activates STAT5 on the ER. Figure $6 f$ shows that the effects of BFA and tunicamycin a

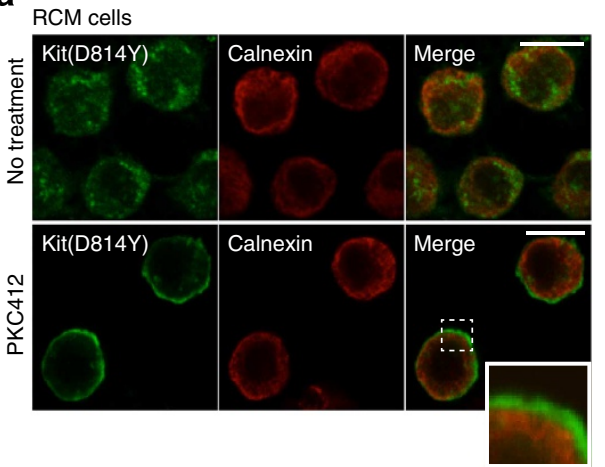

b

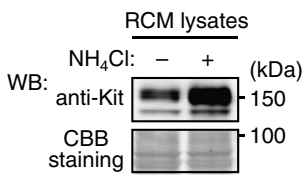

d

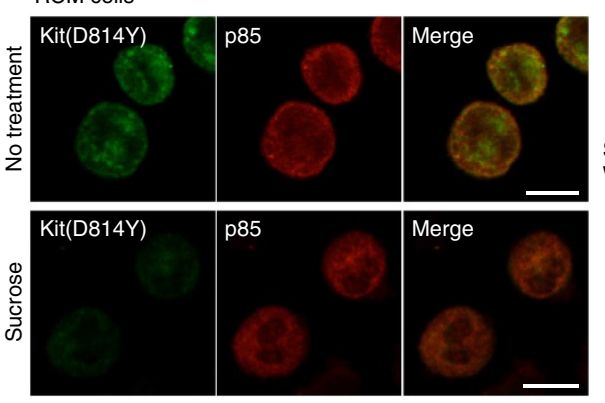

e RCM cells

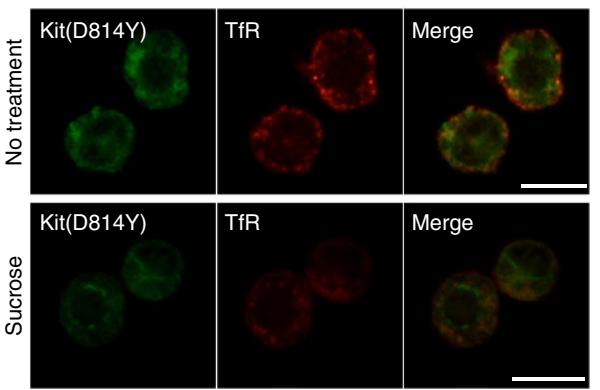

f

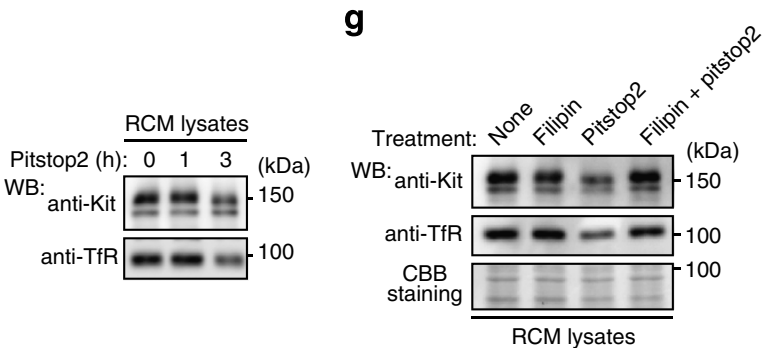

h
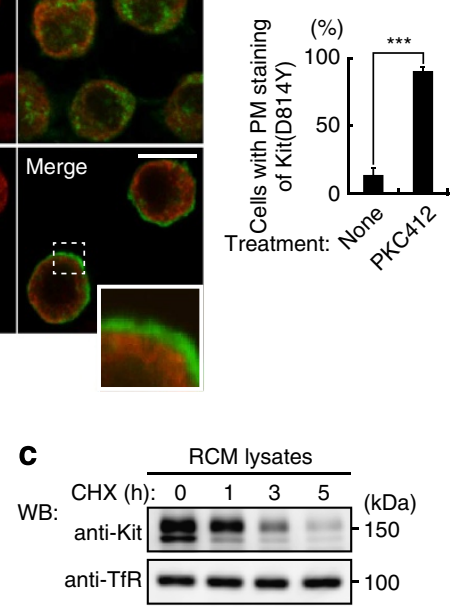

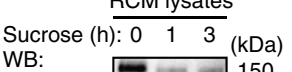
anti-Kit $=\ldots$ anti-p85 - - 75 anti-TfR $=-100$
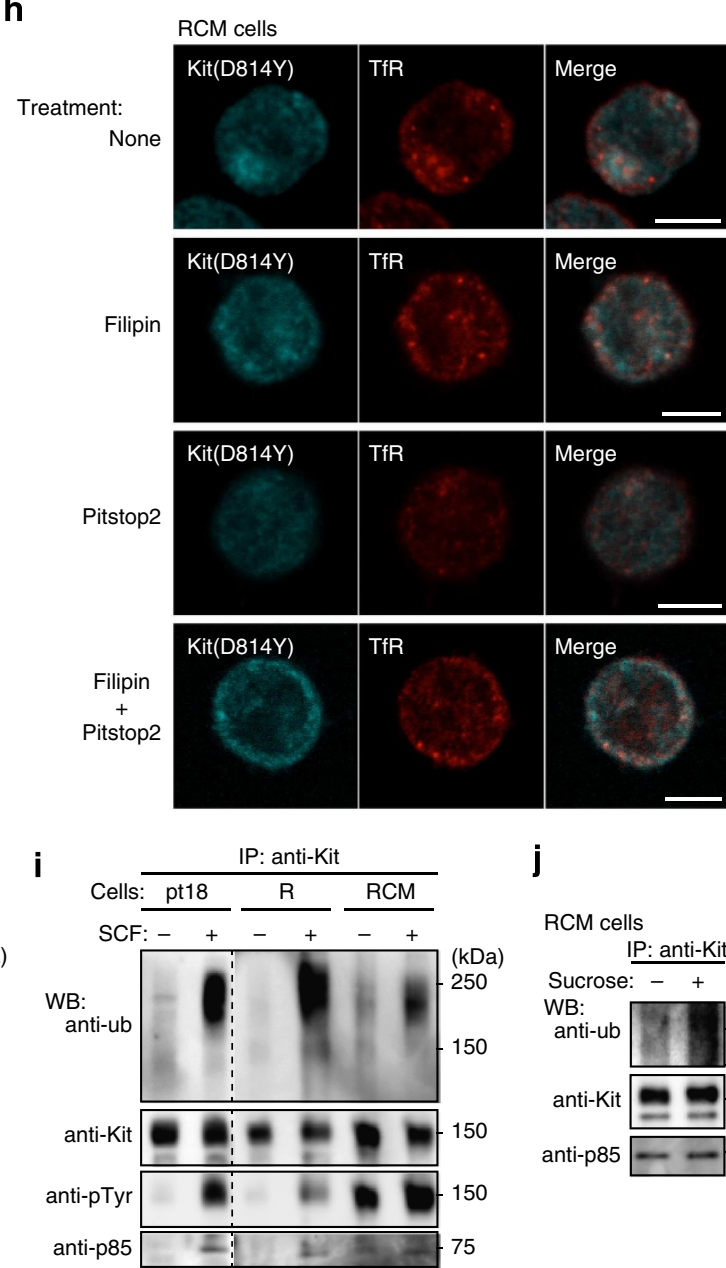

j

RCM cells

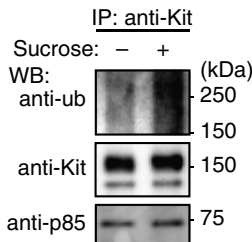

k

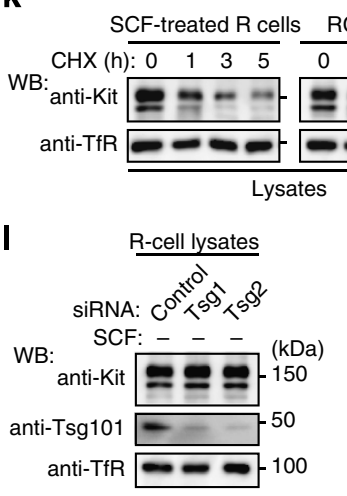

Kit(D814Y) SCF-treated Kit (wt)

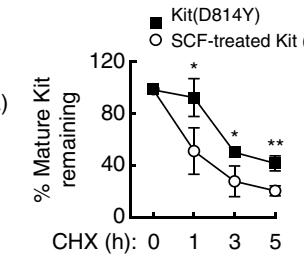

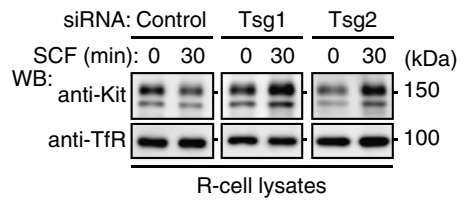

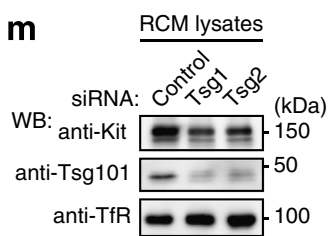



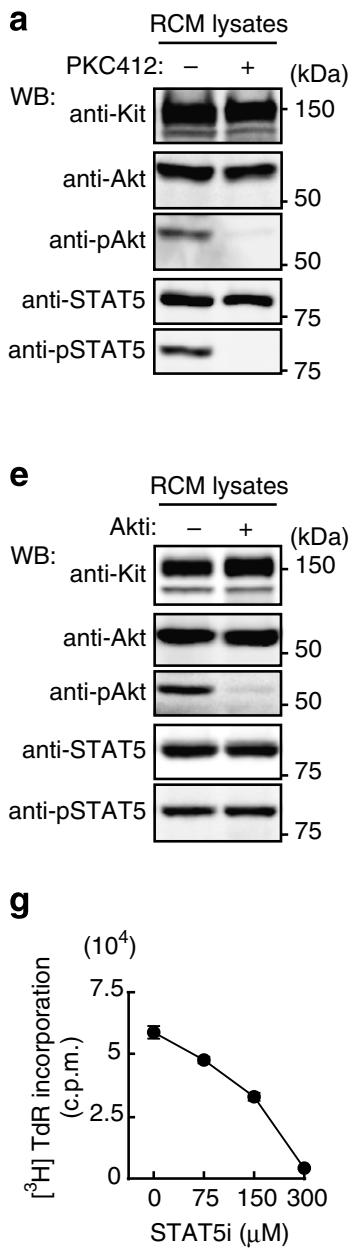
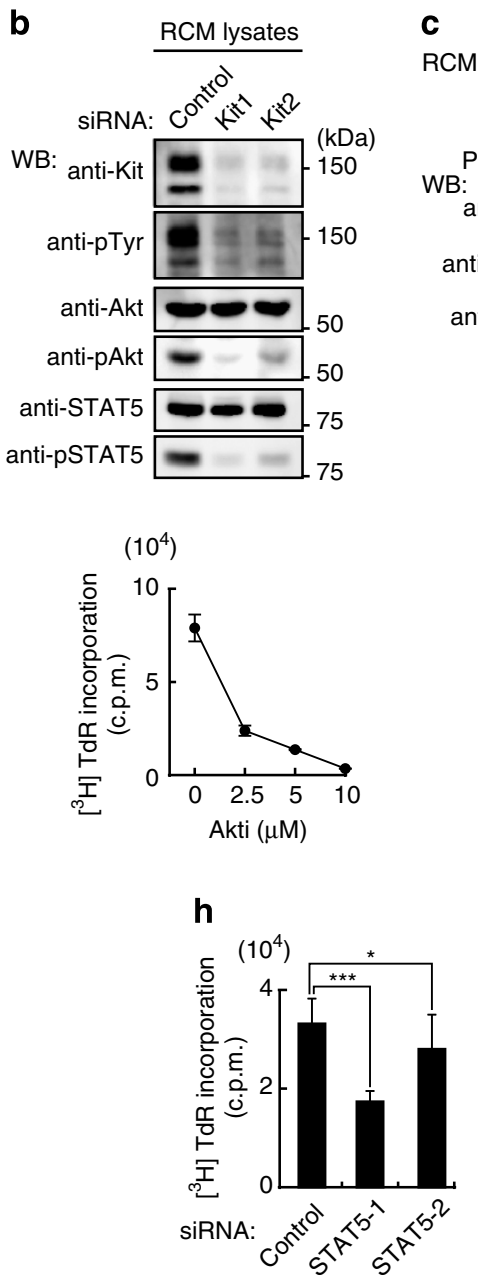

C
RCM cells
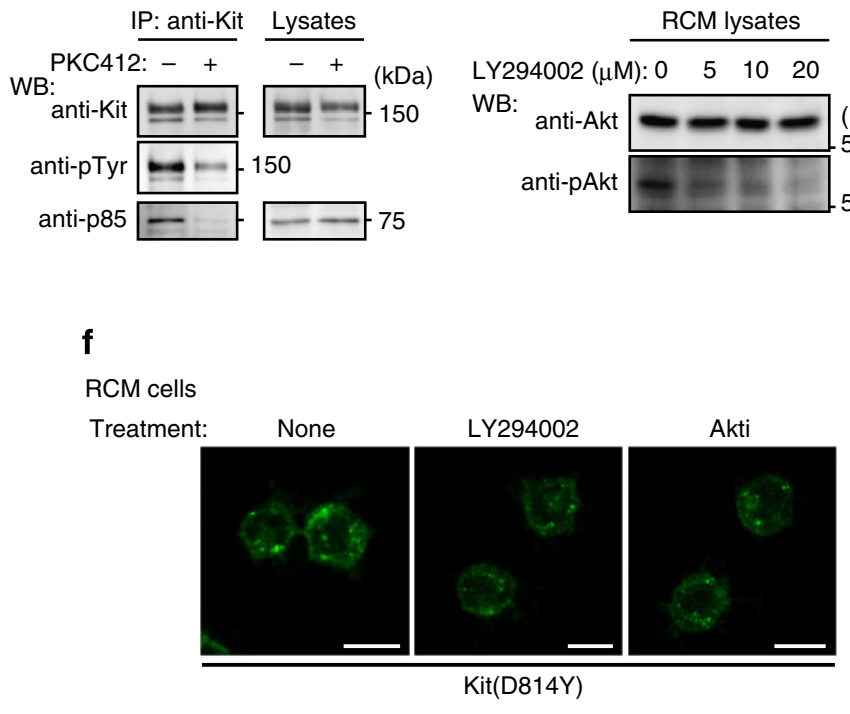

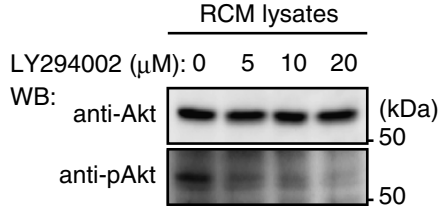

LY294002 ( $\mu$ M): $0 \quad 5 \quad 10 \quad 20$

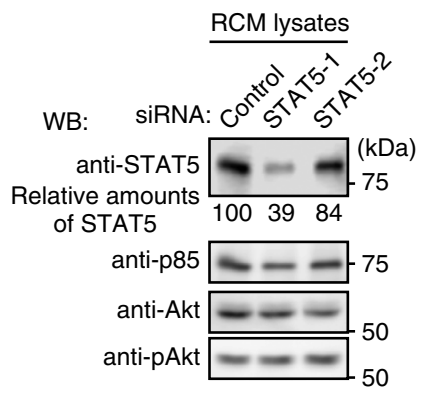

Figure 4 | In mouse RCM cells, Akt and STAT5 must be permanently active for autonomous proliferation. (a,b) Constitutive activation of Akt and STAT5 by Kit(D814Y). (a) RCM cells were treated with $1 \mu \mathrm{M}$ PKC412 (Kit kinase inhibitor) for $24 \mathrm{~h}$, lysed, then immunoblotted. (b) RCM cells transfected with control siRNA or Kit siRNAs were cultured for $20 \mathrm{~h}$, then immunoblotted. (c) Association of Kit(D814Y) with PI3K. RCM cells were treated with $1 \mu \mathrm{M}$ PKC412 for $24 \mathrm{~h}$. Anti-Kit immunoprecipitates (left) and lysates (right) were then immunoblotted. NB: Kit(D814Y) was dissociated from p85 by PKC412 treatment. (d) Activation of Akt by PI3K. RCM cells were treated with the PI3K inhibitor LY294002. Lysates were then immunoblotted. (e) Role of Akt in proliferation of RCM cells. RCM cells treated with $10 \mu \mathrm{M}$ Akti (Akt inhibitor) were cultured for $24 \mathrm{~h}$. (Left) Lysates were then immunoblotted. (Right) [ ${ }^{3} \mathrm{H}$ ]thymidine incorporation. Results (c.p.m.) represent means \pm s.d. $(n=3)$. (f) Effect of LY294002 and Akti on Kit(D814Y) localization. RCM cells were treated with $20 \mu \mathrm{M} \mathrm{LY} 294002$ or $10 \mu \mathrm{M}$ Akti for $24 \mathrm{~h}$ and stained with anti-Kit. Bars, $10 \mu \mathrm{m}$. (g,h) Role of STAT5 in proliferation of RCM cells. (g) [ ${ }^{3} \mathrm{H}$ ]thymidine incorporation into RCM cells treated with the STAT5 inhibitor STAT5i for 24 h. Results (c.p.m.) are means \pm s.d. ( $n=3$ ). (h) RCM cells transfected with control siRNA or STAT5 siRNAs (STAT5-1 and STAT5-2) were cultured for $24 \mathrm{~h}$. (Left) Bar graph shows the levels of [ ${ }^{3} \mathrm{H}$ ]-thymidine incorporation into RCM cells. Results (c.p.m.) are means \pm s.d. $(n=11)$. Data were subjected to one-way ANOVA with Dunnett's multiple comparison posthoc test. ${ }^{\star} P<0.05 ;{ }^{\star \star \star} P<0.001$. (Right) Lysates were immunoblotted. Amounts of STAT5 are expressed relative to control cell lysate after normalization with $\mathrm{p} 85$.

Figure 5 | Kit(D814Y) traffics to endolysosomes to activate Akt in mouse cells. (a) Endolysosomes from RCM cells were immunoprecipitated with control or anti-LAMP1, then immunoblotted. (b,c) RCM cells were transfected with PH-GFP or PH(R25C)-GFP. (b) Expressed proteins were visualized by GFP fluorescence. Phase contrast images are shown. Bars, $10 \mu \mathrm{m}$. (c) Cells were cultured for $1 \mathrm{~h}$ with $1 \mathrm{mg} \mathrm{ml}^{-1}$ AF647-dextran (a marker for endocytic compartments). Bars, $10 \mu \mathrm{m}$. The graph shows Pearson's R correlation coefficient between dextran and expressed proteins. Results are means \pm s.d. from 19 or 21 cells. ${ }^{\star \star} P<0.01$, Student's t-test. (d) RCM cells were co-stained for Kit(D814Y) (green) and phosphorylated Akt (pAkt; red). Bar, $5 \mu$ m. (e-g) RCM cells were cultured with $100 \mathrm{nM}$ BafA1 (blocks endosomal trafficking) or $20 \mathrm{mM} \mathrm{NH}_{4} \mathrm{Cl}$ (blocks proteases) for $24 \mathrm{~h}$. (e) Cells stained with anti-Kit (green) and anti-LAMP1 (endolysosome marker; red). Bars, $10 \mu \mathrm{m}$. The graph shows Pearson's R correlation coefficient between Kit(D814Y) and LAMP1. Results are means \pm s.d. $(n=10 \sim 22)$. Data were subjected to one-way ANOVA with Dunnett's multiple comparison post-hoc test. ${ }^{\star \star \star} P<0.001 ; N S$, not significant. (f) Immunoblots of anti-Kit immunoprecipitates and cell lysates. (g) Immunoblots, RCM cells treated with $100 \mathrm{nM}$ BafA1 for the indicated periods. (h) After 3-h treatment with $100 \mathrm{nM}$ BafA1, R cells were stimulated with $50 \mathrm{ng} \mathrm{ml}{ }^{-1} \mathrm{SCF}$ for the indicated periods in the presence of BafA1, then immunoblotted. The graph shows the percentage of pAkt after nomalization with control at 5-min stimulation. Results (\%) represent means \pm s.d. from three independent experiments. BafA1 did not affect pAkt significantly (Student's $t$-test). (i) Immunoblots, endolysosomes from R cells treated with $50 \mathrm{ng} \mathrm{ml}^{-1} \mathrm{SCF}$ as indicated. (j,k) R cells were stimulated with $50 \mathrm{ng} \mathrm{ml}^{-1}$ SCF for 5 or 60 min. Expressed proteins, Kit(wt) or pAkt are shown. Bars, $10 \mu \mathrm{m}$. The graph shows the number of Kit $(+)$ vesicles with pAkt. Results (\%) represent means \pm s.d $(n=8 \sim 14)$. NS, not significant; ${ }^{\star \star \star} P<0.001$, Student's $t$-test. $\mathrm{ND}=$ not detected. 
a

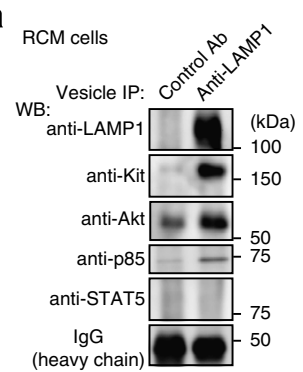

b

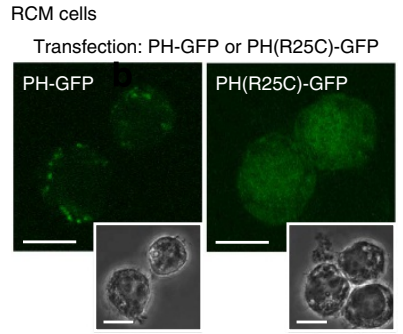

\section{g}

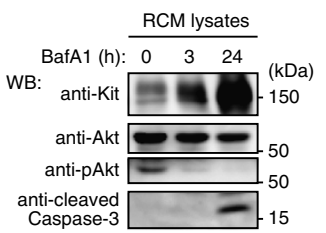

C RCM cells transfected with PH-GFP or $\mathrm{PH}(\mathrm{R} 25 \mathrm{C})$-GFP
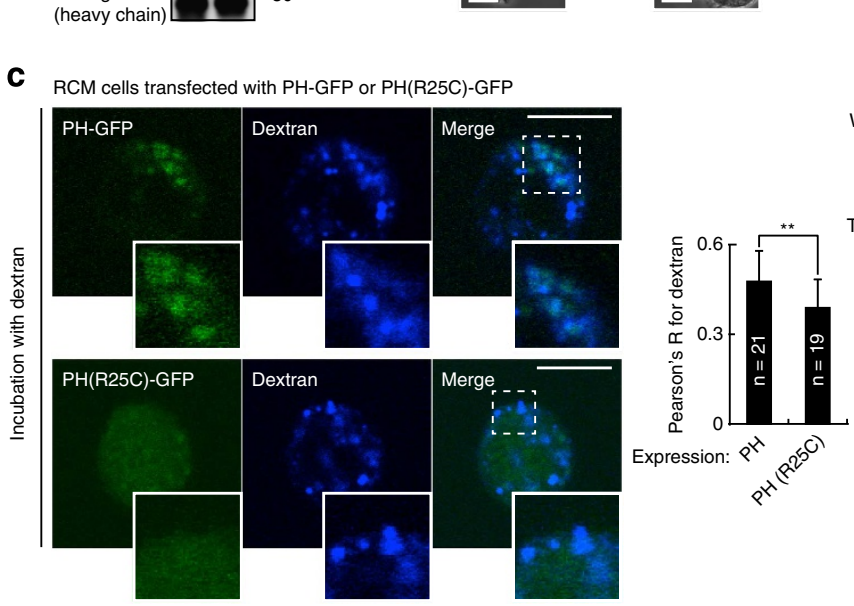

d RCM cells

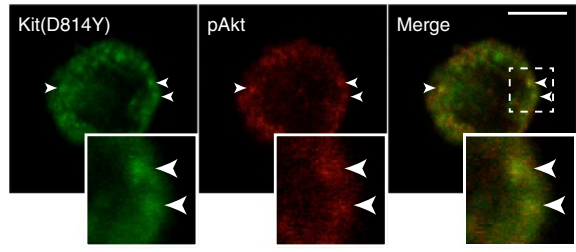

e RCM cells
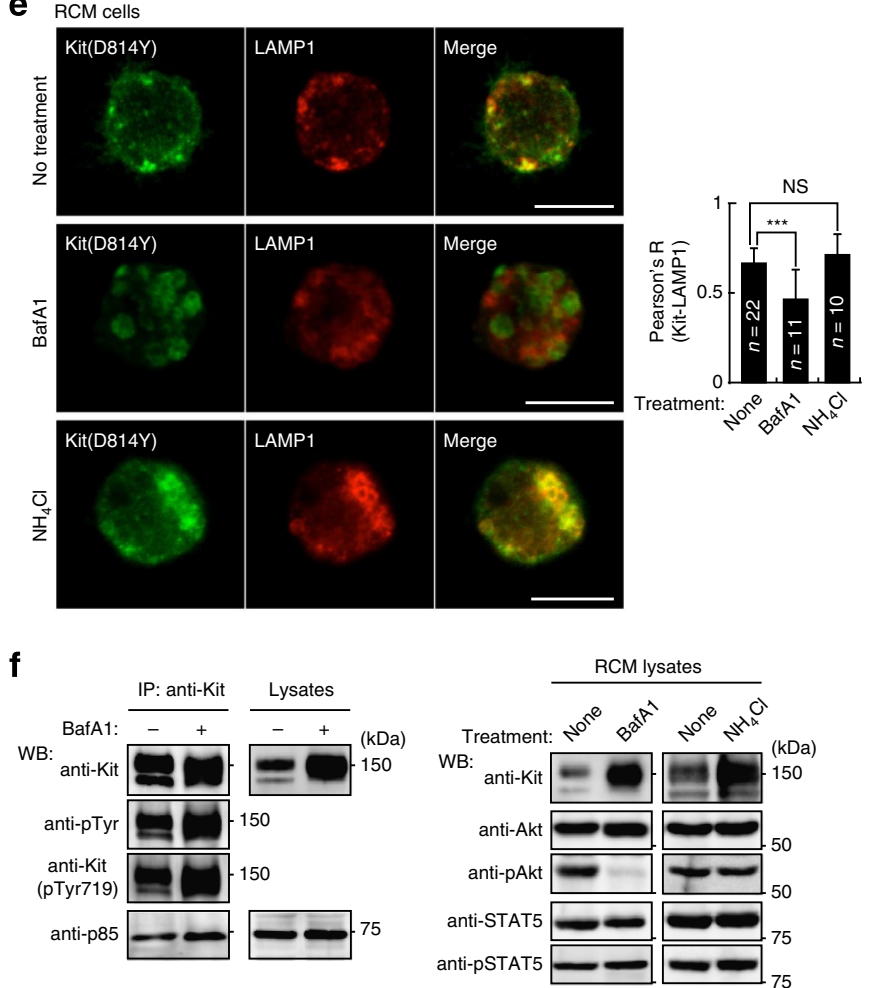

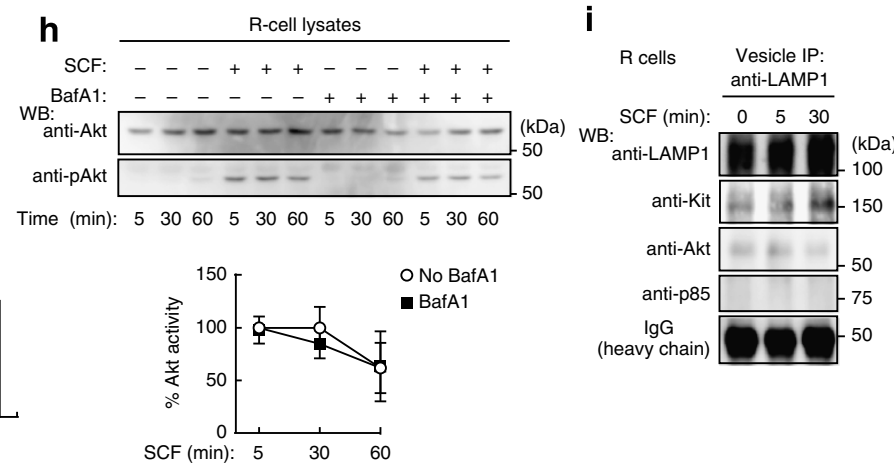

j

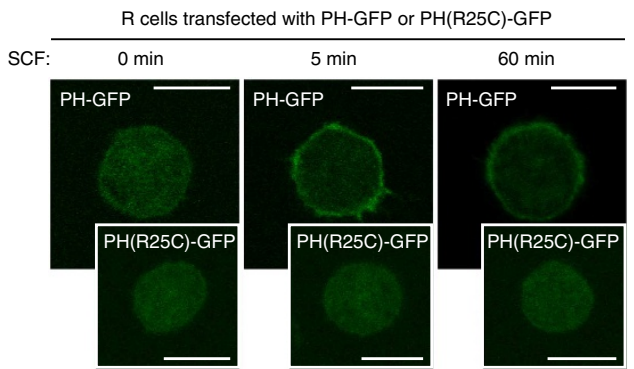

$\mathbf{k}$
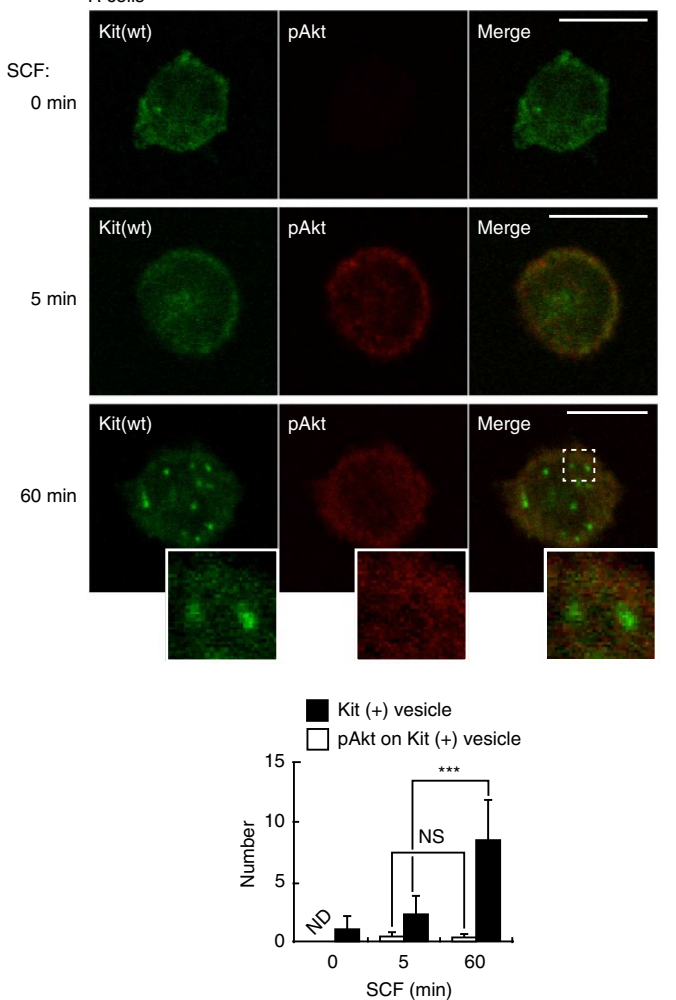
on Akt and STAT5 resulted from accumulation of Kit(D814Y) at the ER, not from apoptosis. In contrast to Kit(D814Y), in R and pt18 cells, SCF stimulation of Kit(wt) did not activate STAT5 (Fig. 6g), as previously described ${ }^{27,29}$. Accumulation of Kit(wt) on the ER did not affect STAT5 activation (Fig. 6h and Supplementary Fig. 5g), indicating that STAT5 activation requires ER-localized Kit(D814Y). Taken together, these results suggest that newly synthesized partially glycosylated Kit(D814Y) on the ER activates STAT5 aberrantly.

Treatment with monensin or BafAl for $3 \mathrm{~h}$ inhibited Akt independently of apoptosis, and activated STAT5 transiently (Figs 5g and 6i; Supplementary Fig. 5h). These drugs did not enhance STAT5 activity in R cells (Fig. 6j and Supplementary Fig. 5i). These results indicate that accumulated Kit(D814Y) on the Golgi and endosomes can activate STAT5 activation transiently. Thus, mechanisms of negative regulation for STAT5 may exist on the Golgi and endosomes.

The oncogenic role of Kit and its trafficking in rat and human cells. Next, we investigated whether the oncogenic role of $\mathrm{Kit}(\mathrm{D} 814 \mathrm{Y})$ and its trafficking seen in RCM cells occur widely in neoplastic mast cells. The human and rat mast cell leukemia cell lines HMC-1 and RBL-2H3 endogenously express Kit with mutations in the kinase domain, these being Kit(D816V) and Kit(D817Y), respectively (Fig. 7a) ${ }^{12,13}$. In these lines, as with RCM, the kinase inhibitor PKC412 blocked Kit kinase activity and cell proliferation (Fig. 7b,c). Most mutant Kit was present as a complex-glycosylated form (Fig. 7d) that significantly co-localized with endolysosomal markers cathepsin D or LAMP1, rather than calnexin (ER) or GM130 (Golgi) (Fig. 7e,f). In HMC-1 cells, antiKit staining shows a pattern similar to that of expressed Kit(D814Y)-GFP but not to Kit(wt)-GFP (Supplementary Fig. 6a), confirming the endolysosomal Kit(D816V) staining.

We next examined Kit trafficking to endolysosomes in these cells. Figure $7 \mathrm{~g}$ shows that PKC412 inhibited trafficking from the PM to endolysosomes, consistent with our findings on Kit(D814Y). Furthermore, for endocytosis, CME inhibition by sucrose reduced the protein levels of Kit but not of p85; in contrast, NCE inhibition by filipin did not affect the protein levels (Fig. 7h and Supplementary Fig. 6b). This suggests that in HMC-1 and RBL-2H3 cells, as in RCM cells, Kit also undergoes CME. Taken together, these results suggest that, in HMC-1 and RBL$2 \mathrm{H} 3$, Kit's oncogenic role and intracellular trafficking are similar to those in RCM cells.

Kit signalling occurs in distinct compartments in human and rat cells. Next, we examined the subcellular location for signalling in HMC-1 and RBL-2H3. As in RCM, oncogenic activation of Akt and STAT5 was also seen and was prevented by PKC412
(Fig. 8a and Supplementary Fig. 6c). Blockade of Kit trafficking to endolysosomes by BafAl for $24 \mathrm{~h}$ also suppressed the activation of Akt but not of STAT5 (Fig. 8b and Supplementary Fig. 6d), indicating that endolysosomal localization of Kit is essential for Akt activation. Blockade of ER export of Kit by BFA for $16 \mathrm{~h}$ suppressed Akt activation, but enhanced STAT5 activation (Fig. 8c). Collectively, these results suggest that in HMC-1 and RBL-2H3 cells, as in RCM cells, partially glycosylated Kit aberrantly activates STAT5 on the ER.

\section{Discussion}

In contrast to normal Kit, which signals from the PM, mutant oncogenic Kit signals from intracellular compartments (Fig. 8d). Newly synthesized, incompletely glycosylated mutant Kit initially localizes to the ER then activates STAT5. Subsequently, mutant Kit traffics to the PM through the Golgi along the secretory pathway and then immediately undergoes CME due to its kinase activity. It then accumulates in endolysosomes, but is not fully ubiquitinated. Mutant Kit is constitutively associated with PI3K, but the complex activates Akt only on the cytoplasmic surface of endolysosomes. In addition to previous reports $25,26,30-33$, our study shows that the oncogenic signalling from mutant Kit is spatially distinct from normal signalling. By comparing RCM with $\mathrm{R}$ cells, we believe that our results show the significance of the unusual Kit localization seen in neoplastic mast cells.

Compartment-dependent oncogenic signalling by constitutively active growth factor receptors has occasionally been reported before. In multiple myeloma cells, deregulated FGF receptor 3 mutants accumulate at the Golgi, and initiate Erk1/2 and STAT1/3 signalling ${ }^{22,27}$. Oncogenic gp130 activates STAT3 not only on the ER but also on endosomes in hepatocytes ${ }^{59}$. In acute myeloid leukemia, the oncogenic Flt3 mutant Flt3-ITD activates STAT5 only on the $\mathrm{ER}^{25-27}$, as shown here for mutant Kit. Kit(D816V) directly tyrosine-phosphorylates STAT proteins in vitro $^{21}$, suggesting that STAT5 might act as a substrate for ERlocalized mutant Kit. The Kit-STAT5 complex might escape from negative regulators such as protein tyrosine phosphatases on the ER but not on the Golgi, endosomes or the PM. The signalling platform may depend on the receptor and type of cell. These studies support our model that oncogenic Kit signalling occurs only on specific intracellular compartments in neoplastic mast cells. In leukaemia, mutant Kit participates in the PI3K-Akt pathway, in STAT5 activation, in the RhoA-Rho kinase pathway ${ }^{47}$ and in activation of Src-like adaptor protein ${ }^{60}$, and there is great interest in further understanding the spatial organization of this signalling.

Mutant Kit associates with PI3K throughout its intracellular trafficking, but only activates Akt when on endolysosomes. The PI3K product $\mathrm{PI}(3,4,5) \mathrm{P}_{3}$, which is required for Akt activation, is

Figure 6 | Kit(D814Y) at the ER activates STAT5 in mouse cells. (a,b) Inhibition of export of Kit(D814Y) from the Golgi. RCM cells were cultured with $250 \mathrm{nM}$ monensin (inhibits Golgi transport) for $24 \mathrm{~h}$. (a) RCM cells were stained with anti-Kit (green) and anti-GM130 (Golgi marker, blue). Magnified images of the boxed area are shown. Bars, $10 \mu \mathrm{m}$. The graph shows correlation coefficient (Pearson's R) between Kit and GM130. Results are means \pm s.d. from 15 cells. ${ }^{\star \star \star} P<0.001$, Student's t-test. (b) Immunoblots of anti-Kit immuoprecipitates (left) and cell lysates (right). (c-e) Inhibition of export of Kit(D814Y) from the ER. RCM cells were cultured with $1 \mu \mathrm{g} \mathrm{ml}{ }^{-1}$ tunicamycin for $24 \mathrm{~h}$, or $5 \mu \mathrm{M}$ BFA for $16 \mathrm{~h}$ to block ER export. (c) RCM cells were stained with anti-Kit (green) and anti-calnexin (ER marker; red). Magnified images of the boxed area are shown. Bars, $10 \mu \mathrm{m}$. The graph shows the correlation coefficient (Pearson's R) between Kit and calnexin. Results are means \pm s.d. from 11 to 13 cells. Data were subjected to one-way ANOVA with Dunnett's multiple comparison post-hoc test. ${ }^{* \star} P<0.001$. (d) Immunoblots of anti-Kit immuoprecipitates and cell lysates. NB: ER-localized Kit(D814Y) activated STAT5. (e) BFA-treated cells were stained with anti-Kit (green) and anti-STAT5 (red) antibodies. Magnified images of the boxed area are shown. Bars, $10 \mu \mathrm{m}$. The graph shows the correlation coefficient (Pearson's R) between Kit and STAT5 in the non-nuclear region. Results are means \pm s.d. from 16 cells.

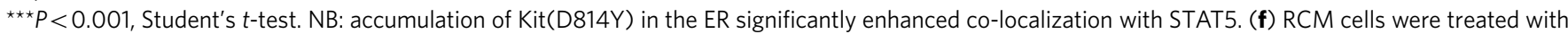
$5 \mu \mathrm{M}$ BFA, $1 \mu \mathrm{g} \mathrm{ml}^{-1}$ tunicamycin, $250 \mathrm{nM}$ monensin or $100 \mathrm{nM}$ BafA1 for the indicated periods and then immunoblotted. (g) Starved R cells (left) or pt18 cells (right) stimulated with $50 \mathrm{ng} \mathrm{ml}^{-1} \mathrm{SCF}$ for $5 \mathrm{~min}$ then lysed and immunoblotted. NB: normal Kit was unable to activate STAT5. (h-j) RCM cells or starved R cells treated with $250 \mathrm{nM}$ monensin or $5 \mu \mathrm{M}$ BFA for the indicated periods, then immunoblotted. CG = complex-glycosylated form; $\mathrm{DG}=$ deglycosylated form; $\mathrm{HM}=$ high mannose form. 
a RCM cells
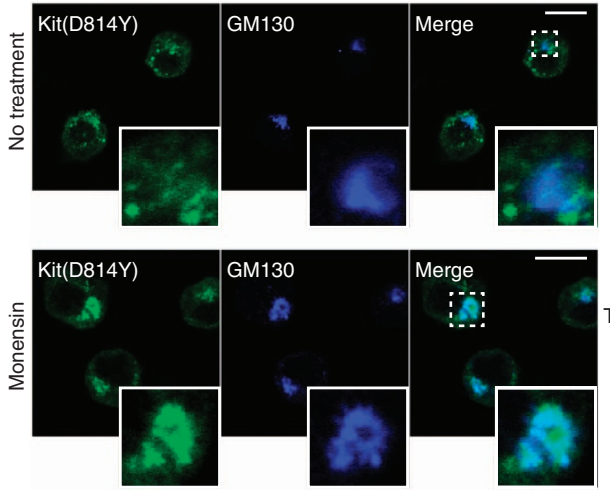

b

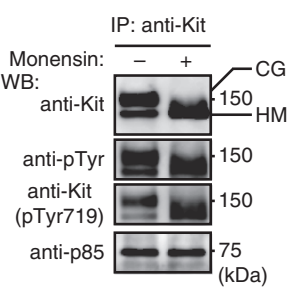

C RCM cells
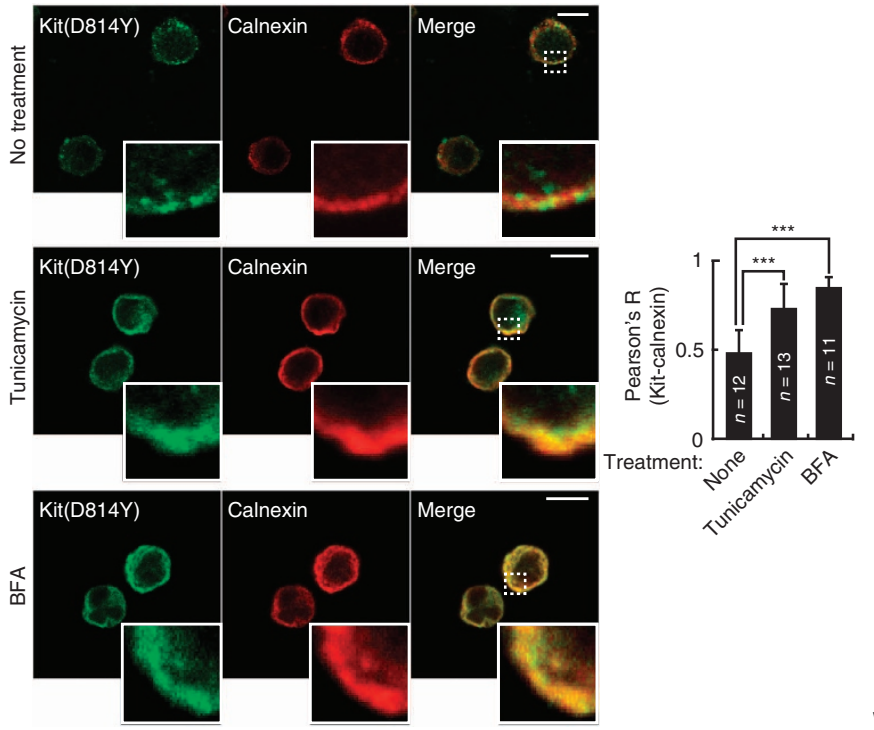

d
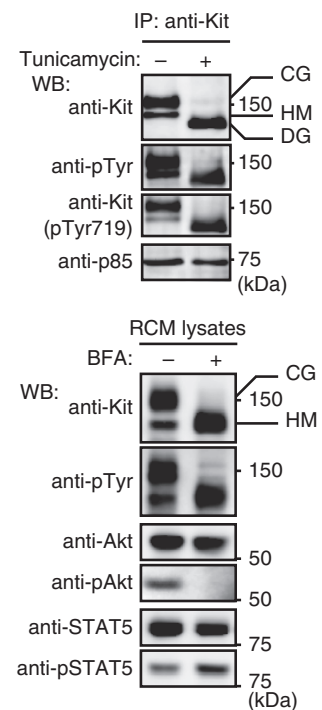

e RCM cells

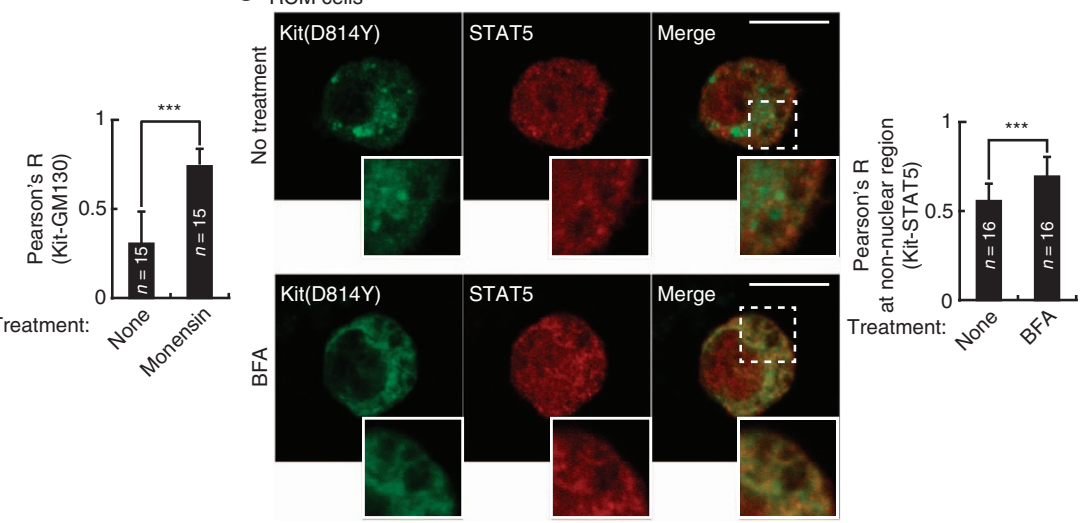

f

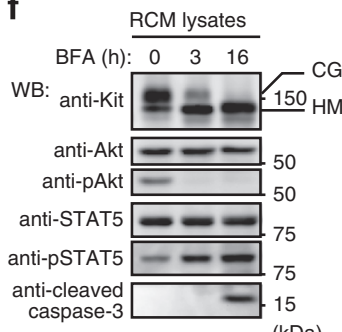

(kDa)
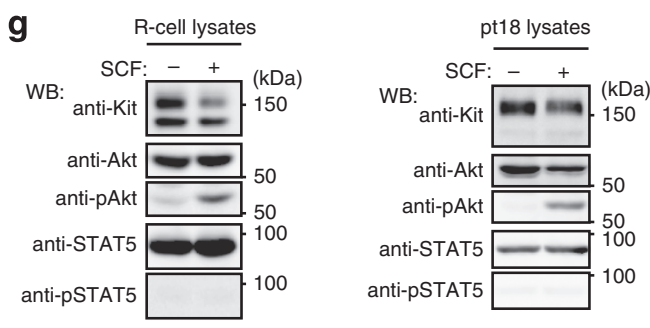

\section{$\mathbf{h}$}

BFA (h): $\begin{array}{lll}0 & 3 & 12\end{array}$
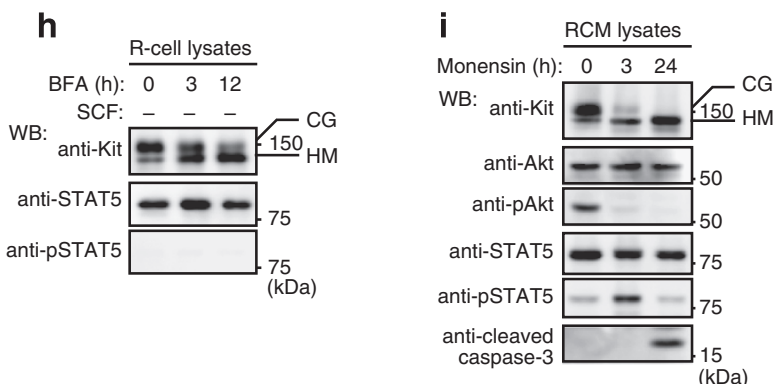

j

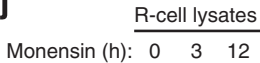

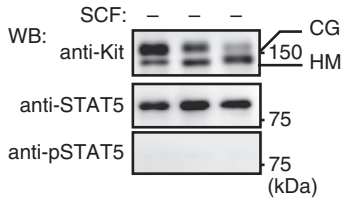

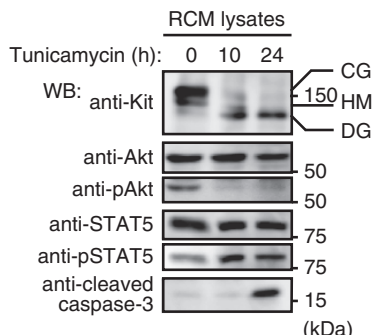

(kDa) 
believed to be generated solely at the $\mathrm{PM}^{54,61,62}$. However, $\mathrm{PI}(4,5) \mathrm{P}_{2}$, a substrate of $\mathrm{PI} 3 \mathrm{~K}$, is generated by phosphatidylinositide-4-phosphate-5-kinase on LAMP1-positive structures for proto-lysosome homeostasis ${ }^{63,64}$ and plays a role in endosome-to-lysosome trafficking ${ }^{52}$. The following observation is also relevant: when SCF binds Kit at the PM, Kit activates inositol-5-phosphatase, which dephosphorylates $\mathrm{PI}(3,4,5) \mathrm{P}_{3}$, and so terminates Akt signalling ${ }^{10}$. The significance is that, unlike normal Kit, mutant Kit cannot activate Akt at the PM. Further studies will be required to understand the mechanism by which the Kit-PI3K complex activates Akt selectively on endolysosomes.

In this study, CME stabilized mutant Kit on endolysosomes. This agrees with previous data showing that CME is essential for sustained signalling from Met, TGF $\beta R$ and EGFR $^{24,37-39,50}$. However, mutant Kit was barely found in recycling endosomes, where the other receptors localize after ligand stimulation, and then recycle back to the PM. As very little SCF-bound normal Kit and mutant Kit recycle back to the $\mathrm{PM}^{33,45}$, CME must lead to at least two different pathways: the endolysosomal pathway leading to receptor destruction and the recycling endosome pathway, leading to receptor recycling. Ubiquitination of mutant Kit is insufficient for its rapid degradation. Defects in the tumour suppressor protein $\mathrm{Cbl}$, an E3-ubiquitin ligase, also slow the degradation of Kit and Flt3, and prolong the activation of Akt, resulting in mastocytosis and myelo-proliferative disease ${ }^{43,65,66}$. When the CME pathway was blocked, mutant Kit was sorted into NCE and normally ubiquitinated. Neoplastic transformation might also involve an inappropriate sorting mechanism that recruits mutant Kit predominantly into CME not NCE. At present, we cannot explain why.

After SCF stimulation, Kit(wt) is transported into lysosomes in a manner dependent on ESCRT. This is consistent with previous reports that ESCRT transports ubiquitinated cargos $44,46,52$. ESCRT inhibition, however, does not cause accumulation of Kit(D814Y). Importantly, a recent study described that underubiquitinated cargos are incorporated into lysosomes in a manner independent of ESCRT ${ }^{46}$. Our results suggest that the mechanism of endosome-lysosome trafficking for mutant Kit is different from that for Kit(wt). Other mutant RTKs, such as EGFR(L858R) ${ }^{23}$, $\operatorname{Met}(\mathrm{D} 1246 \mathrm{~N})^{24}$ and Flt3(D835Y) ${ }^{25}$, might also escape from ESCRT-dependent trafficking.

Imatinib, a Kit inhibitor used as a drug, is efficacious in most patients with gastrointestinal stromal tumours harbouring Kit mutations in the juxta-membrane region ${ }^{4,11,14}$. However, imatinib is ineffective for most human mast cell tumours with Kit mutations in the kinase domain ${ }^{20,29,67}$. Moreover, during imatinib treatment of the gastrointestinal tumours, mutations often develop in the Kit kinase domain ${ }^{14}$. Imatinib-resistant gastrointestinal tumour cells depend on activation of the PI3KAkt pathway by Kit mutants for their proliferation, and so resemble mast cells ${ }^{68}$.
In this study, we showed that, in mast cells, mutant Kit trafficking to endolysosomes is critical for the activation of Akt. When acute myeloid leukemia cells with constitutively active Flt3 mutants, such as Flt3-ITD and Flt3(D835Y), are treated with statins (HMG-CoA reductase inhibitors), this reduces Akt activation by blocking receptor trafficking towards the $\mathrm{PM}^{25}$. Thus, Kit trafficking could be a new therapeutic target for mast cell tumours, and for imatinib-resistant gastrointestinal tumours. Combined therapy with an antibody and a kinase inhibitor seems attractive. As PKC412 treatment causes mutant Kit to remain at the PM through blocking the Kit kinase activity, it might enhance the activity of anti-Kit antibody ${ }^{69}$. Lapatinib, an EGFR kinase inhibitor, enhances the cytotoxic activity of trastuzumab, an antiErbB2 antibody in vivo ${ }^{70}$.

In conclusion, we show that compartment-dependent oncogenic Kit signalling is necessary for neoplastic mast cell proliferation. These findings provide new insights into the pathogenic role of Kit in neoplastic mast cell disorders. Improper trafficking and aberrant signalling are frequent features of constitutively active growth factor receptors, for which these data will shed light on the significance of the spatial organization of this oncogenic signalling.

\section{Methods}

Cells and stimulation. RCM (R cell, mutant Kit) and R cells were established from splenocytes of DO11.10 mice by repeated stimulation with ovalbumin peptides in vitro. The cell lines exhibited mast cell-like surface phenotype, c-Kit ${ }^{+} \mathrm{Fc \varepsilon RI}^{+}$ and mast cell-like expression profiles of proteases. Moreover, RCM and R cells can secrete biologically active product on stimulation in vitro and in vivo. They do not express SCF. We were unable to find Kit(wt) by cDNA sequencing in RCM cells. For culture of R cells, we used culture supernatants from T-cell lines stimulated with an anti-T cell receptor antibody as a cytokine cocktail. R cells were cultured in $0.25 \%$ cytokine cocktail. RCM cells proliferated without the cocktail and developed tumours in vivo. HMC-1.2 (referred to henceforth as HMC-1), RBL-2H3 and pt18 cells were fro $\mathrm{m}$ Dr Hirohisa Saito and Dr Kenji Matsumoto (National Center for Child Health and Development), Dr Ko Okumura (Juntendo University) and Dr Ryo Goitsuka (Tokyo University of Science), respectively. These cells and RCM cells were cultured at $37^{\circ} \mathrm{C}$ in RPMI 1640 medium supplemented with $10 \%$ fetal calf serum (FCS), penicillin, streptomycin and $50 \mu \mathrm{M} 2$-mercaptoethanol. HMC-1 cells were grown in suspension at $37^{\circ} \mathrm{C}$ in $\alpha$-MEM containing $10 \%$ FCS, penicillin and streptomycin. For stimulation, cells were starved for at least $3 \mathrm{~h}$ and then treated with $50 \mathrm{ng} \mathrm{ml}^{-1}$ recombinant mouse SCF (PeproTech).

Cell proliferation assay. Cells were cultured with inhibitors or cytokines for at least $16 \mathrm{~h}$ and then treated with $\left[{ }^{3} \mathrm{H}\right]$-thymidine deoxyribonucleotide (TdR) for $8 \mathrm{~h}$. Cell proliferation was evaluated by incorporation of $\left[{ }^{3} \mathrm{H}\right]-\mathrm{TdR}$.
Chemicals. PKC412 (Santa Cruz Biotechnology), cytochalasin D (Sigma-Aldrich) tunicamycin (Sigma-Aldrich), cycloheximide (Sigma-Aldrich), filipin (Sigma- Aldrich), Akt inhibitor VIII (Calbiochem), STAT5 inhibitor (Calbiochem), LY294002 (Calbiochem), U0126 (Calbiochem) and pitstop2 (Abcam) were dis- solved in dimethyl sulfoxide. Bafilomycin A1 (Sigma-Aldrich), brefeldin A (Sigma-Aldrich) and monensin (Biomol) were dissolved in ethanol.

Figure 7 | Oncogenic role and intracellular trafficking of mutant Kit in rat and human cells. (a) Mutant Kit is constitutively active in $\mathrm{HMC}-1$ and $\mathrm{RBL}-2 \mathrm{H} 3$ cells. (Left) Schematic structures of Kit in HMC-1 and RBL-2H3 cells. (Right) Immunoblots of anti-Kit immunoprecipitates from HMC-1 or RBL-2H3 cells treated with $1 \mu \mathrm{M}$ PKC412 (Kit kinase inhibitor) for 4 or $12 \mathrm{~h}$, respectively. (b,c) The effect of PKC412 on proliferation. (b) $\left[{ }^{3} \mathrm{H}\right]$-thymidine incorporation in HMC-1 cells treated with PKC412 for 24 h. Results (c.p.m.) are means \pm s.d. $(n=3)$. (c) Growth of RBL-2H3 cells treated with (filled circles) or without (open circles) $1 \mu \mathrm{M}$ PKC412. Results are means \pm s.d. $(n=3)$. (d) Glycosylation of Kit(D816V) and Kit(D817Y) performed as for Fig. 2a. (e,f) Subcellular localization of Kit. (e) Methanol-fixed HMC-1 or (f) PFA-fixed RBL-2H3 cells were double-stained with anti-Kit (green) and anti-cathepsin D (endolysosome marker; red), anti-LAMP1 (endolysosome marker; red), anti-calnexin (ER marker; red), or anti-GM130 (Golgi marker; blue). Magnified images of the boxed area are shown. Representative images of Kit-positive endolysosomes containing cathepsin D are shown. Bars, $5 \mu$ m. The graphs show the correlation coefficient (Pearson's R) between Kit and organelle markers. Results are means \pm s.d. from 15 to 18 cells. Data were subjected to one-way ANOVA with Dunnett's multiple comparison post-hoc test. ${ }^{\star \star} P<0.01,{ }^{\star \star \star} \mathrm{P}<0.001$. (g,h) Endocytosis of mutant Kit in HMC-1 and RBL-2H3 cells. (g) HMC-1 (left) or RBL$2 \mathrm{H} 3$ cells (right) treated with $1 \mu \mathrm{M}$ PKC412 for 4 or $12 \mathrm{~h}$, respectively. Cells were stained with anti-Kit (green) and anti-calnexin (ER marker; red). Insets show boxed areas at higher magnification. Bars, $10 \mu \mathrm{m}$. (h) HMC-1 cells treated with $1 \mu \mathrm{g} \mathrm{ml}{ }^{-1}$ filipin or $0.45 \mathrm{M}$ sucrose for $3 \mathrm{~h}$ to block endocytosis. Cells were stained with anti-Kit (cyan) and anti-p85 (red). Bars, $10 \mu \mathrm{m}$. Immunoblots for Kit, p85 and TfR are shown. 
a

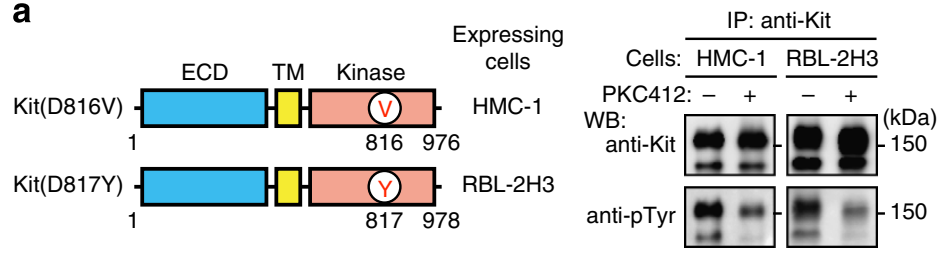

b

HMC-1 cells

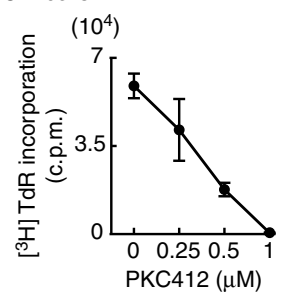

d

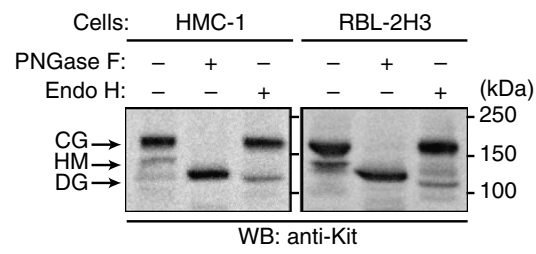

e

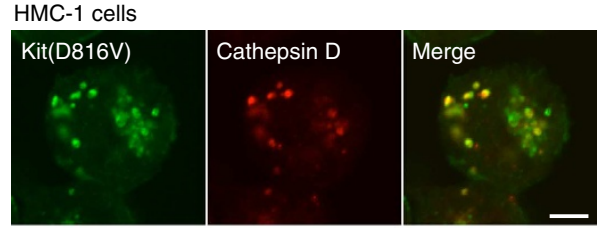

Magnified images of endolysosomal region
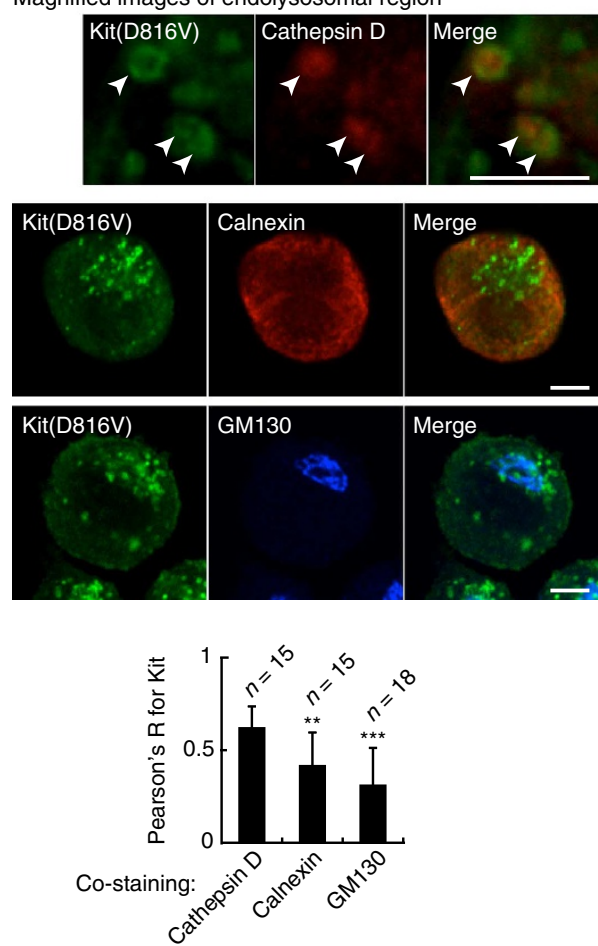

f RBL-2H3 cells
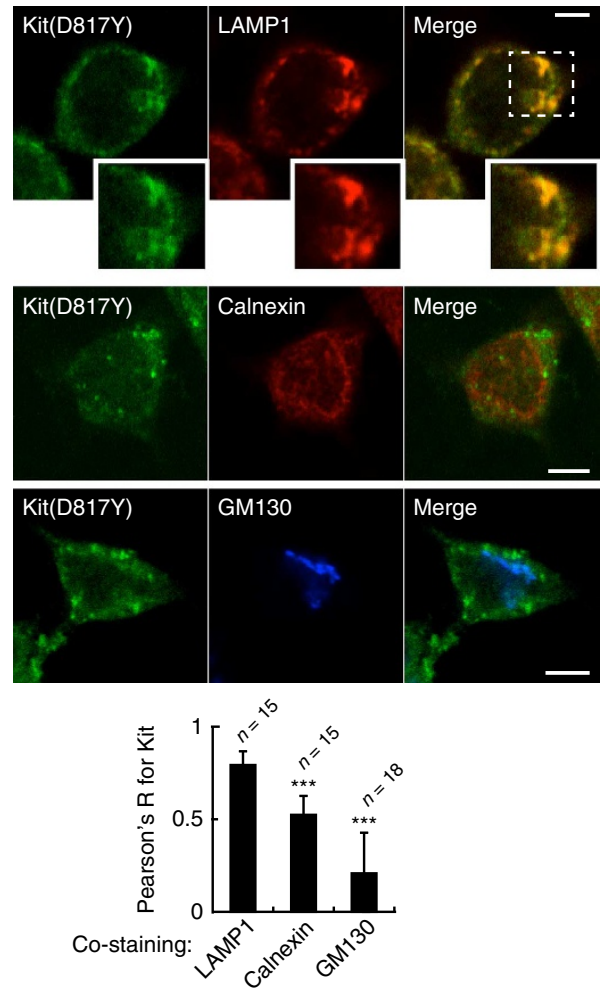

g

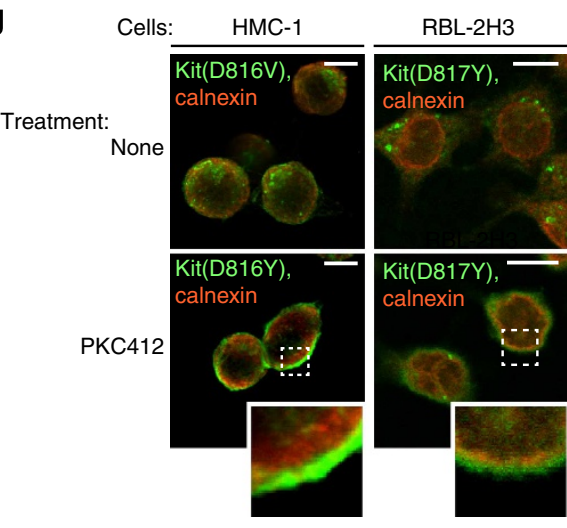

h

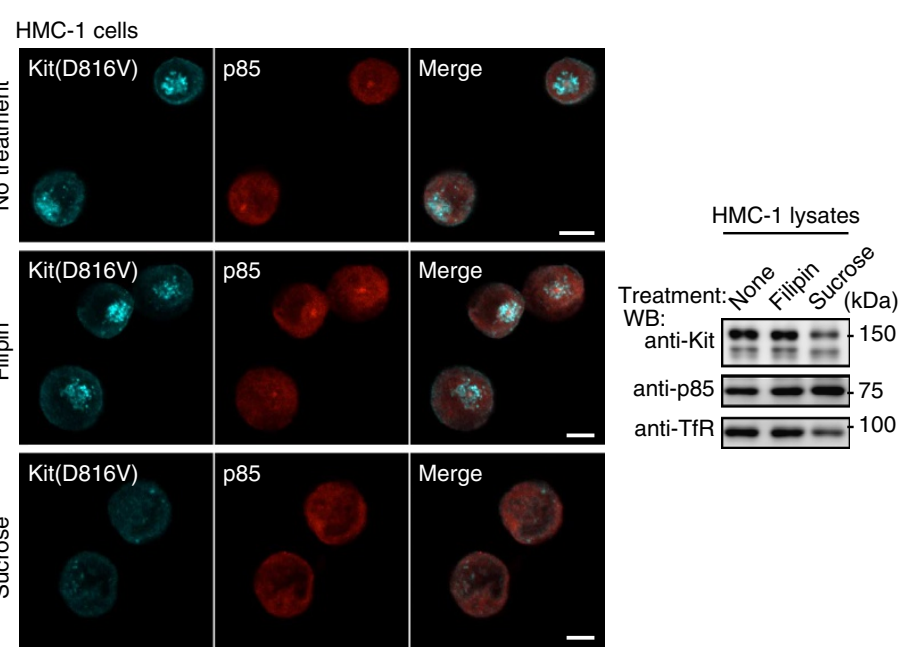


a

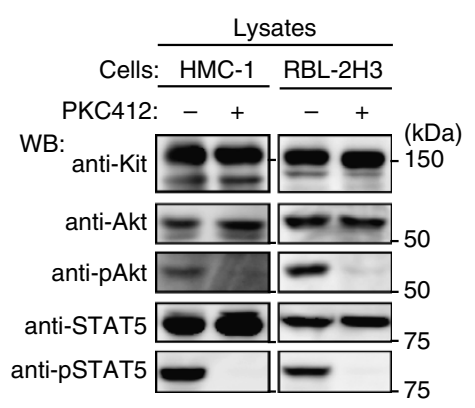

c

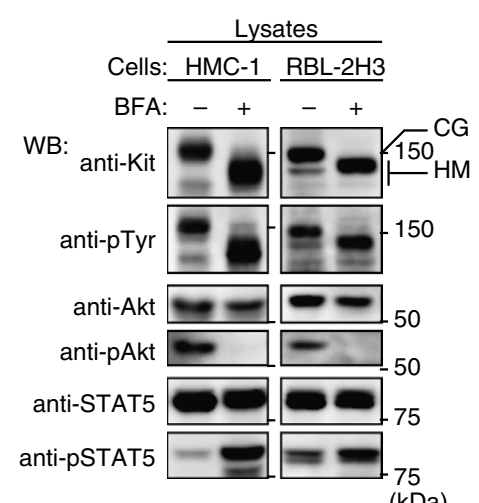

(kDa)
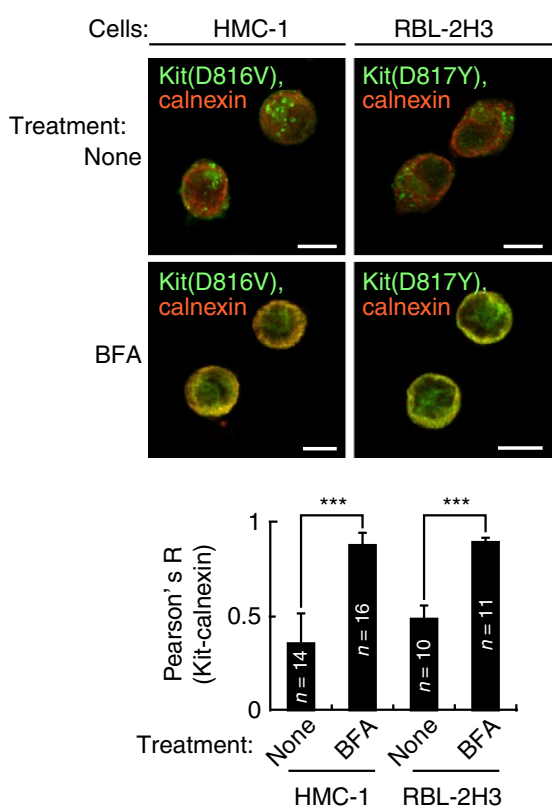

b

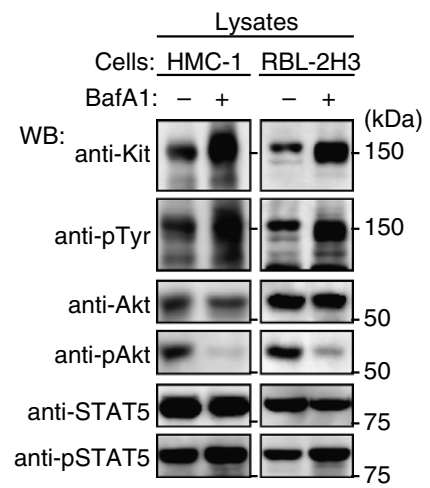

d

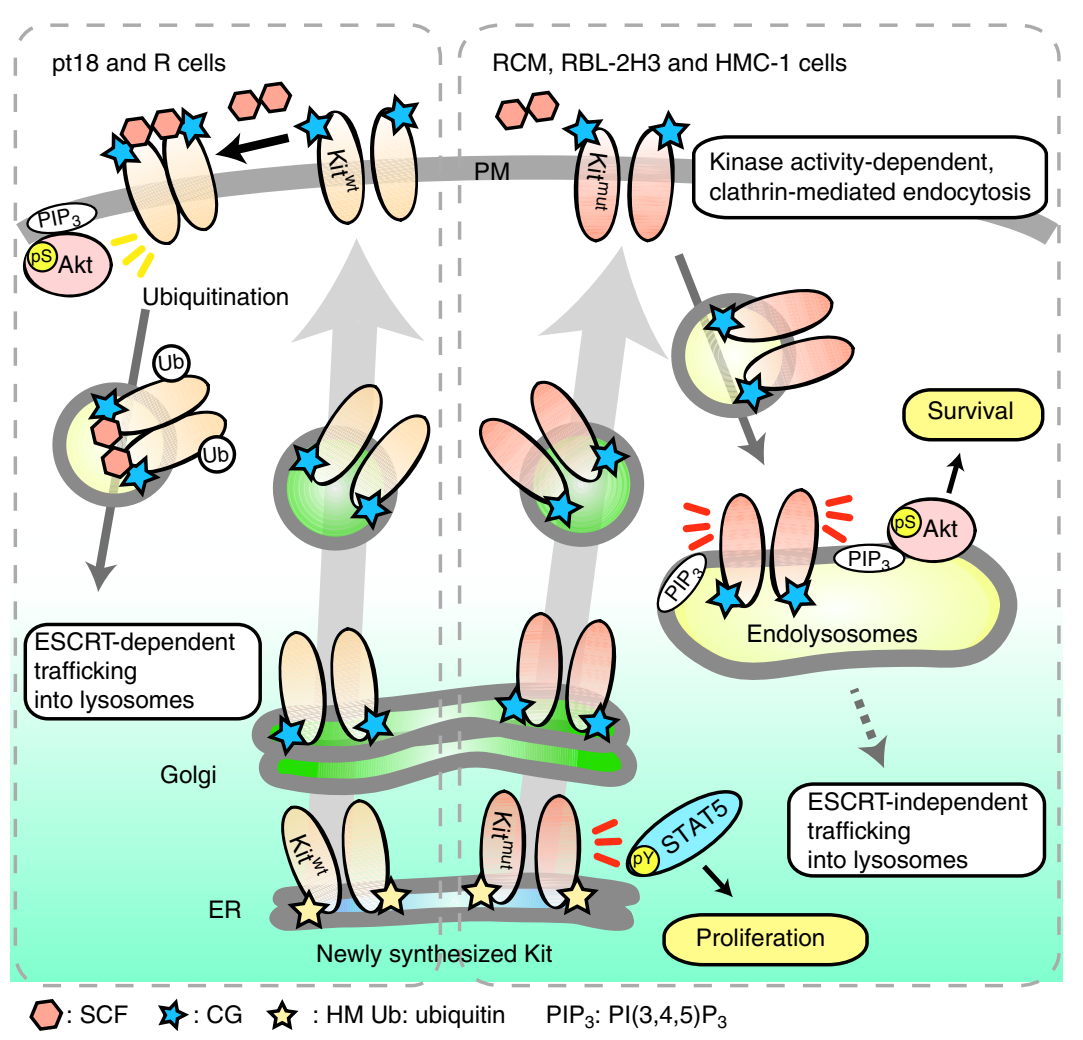

pY, pS: phospho-tyrosine, -serine

Figure 8 | Oncogenic signalling by mutant Kit on endolysosomes and the ER in rat and human cells. (a) Constitutive activation of Akt and STAT5 by mutant Kit in HMC-1 and RBL-2H3 cells. Immunoblots, HMC-1 (left) or RBL-2H3 cells (right) treated with $1 \mu \mathrm{M}$ PKC 412 for 4 or $12 \mathrm{~h}$, respectively. (b) Immunoblots, HMC-1 or RBL-2H3 cells cultured with $100 \mathrm{nM}$ BafA1 for $24 \mathrm{~h}$. (c) (Top) Immunoblots, HMC-1 or RBL-2H3 cells cultured with $5 \mu$ M BFA for $16 \mathrm{~h}$. CG, complex-glycosylated form; HM, high mannose form. (Middle) Cells stained with anti-Kit(green) and anti-calnexin (ER marker; red). Bars, $10 \mu \mathrm{m}$. (Bottom) The graph shows the correlation coefficient (Pearson's R) between Kit and calnexin. Results are means \pm s.d. from 10 to 16 cells. ${ }^{\star \star \star} P<0.001$, Student's $t$-test. (d) Trafficking and signalling from normal Kit (left) and mutant Kit (right). Normal Kit-left panel; newly synthesized Kit traffics from ER, through the Golgi apparatus to the PM. After binding to SCF, Kit activates downstream pathways such as PI3K-Akt mainly at the PM. Kit then becomes endocytosed and ubiquitinated, resulting in ESCRT-dependent incorporation into lysosomes and rapid degradation. Mutant Kit-right panel; soon after synthesis, immature Kit is localized on the ER and activates STAT5. It then traffics to the PM along the secretory pathway, similar to normal Kit. After mutant Kit reaches the PM, it immediately undergoes clathrin-mediated endocytosis in a kinase activity-dependent manner. Kit then accumulates to endolysosomes but is not fully ubiquitinated, so is resistant to degradation. Unlike normal Kit, mutant Kit-PI3K activates Akt specifically on endolysosomes. Mutant Kit does not require ESCRT for incorporation into lysosomes. 
Antibodies. The following antibodies were purchased: c-Kit (M-14), STAT3 (C20), STAT5 (C-17), Erk2 (K-23), Jak2 (C-20), cathepsin D (H-75), CD63 (H-93), actin (I-19) and CD28 (H-193) from Santa Cruz Biotechnology; Kit[pTyr719], Akt, Akt[pSer473], STAT5[pTyr694] (D47E7), cleaved caspase-3 and Erk[pThr202/ pTyr204] (E10) from Cell Signaling Technology; TGN46, EEA1, Rab11, Tsg101 and TfR from Abcam; calnexin and ubiquitin (FK2) from Enzo; GM130 (35) and AP $2 \alpha$ (8) from BD Transduction Laboratories; 885 from Millipore and LAMP1 from Sigma-Aldrich. Anti-phosphotyrosine antibody (4G10) was kindly provided by Dr Toshinori Nakayama (Chiba University). Alexa-fluor 488 anti-Kit (AF488anti-Kit; 2B8; Biolegend) was used for the experiments in Figs $2 \mathrm{~b}$ and $5 \mathrm{k}$. The list of antibodies with source and conditions of immunoblotting and immuno-

fluorescence is shown in Supplementary Table 1. HRP-labelled anti-mouse Ig, antirabbit Ig and anti-goat Ig secondary antibodies were purchased from The Jackson Laboratory. AF488-anti-goat IgG, AF568-anti-rabbit IgG, AF647-anti-goat IgG and AF647-anti-mouse secondary antibodies were obtained from Molecular Probes.

Plasmids. Mouse cDNAs encoding Kit(wt) or Kit(D814Y) were generated by reverse transcription polymerase chain reaction from R or RCM cells, respectively. After deletion of the termination codon, they were fused with GFP from pEGFPN1 (Clontech). For protein expression, constructs were subcloned into the Xho I and Not I sites of pBCMGS (from Dr Hajime Karasuyama, Tokyo Medical and Dental University). PH-GFP or PH(R25C)-GFP subcloned into pEGFP-N1 (ref. 54) were from Dr Tamás Balla (National Institutes of Health) through Addgene. The human p85 N-terminal SH2 domain (325-430) or C-terminal SH2 domain (614-721) subcloned into pGEX-4T-2 (GE Healthcare Life Sciences) were from Dr Masayuki Oda (Kyoto Prefectural University).

Gene silencing with siRNAs. For silencing Kit(D814Y), STAT5B, AP2 $\alpha$ or Tsg101, siRNA duplexes were purchased from Sigma-Aldrich (Kit1: 5'-GAAGGAUUAUGUCAAAUCUTT-3', Kit2: 5'-GACAUGAAGCCUGGCGUUUTT-3', STAT5-1: 5'-GAAUUUGCCAGGACGGAAUTT-3', STAT5-2: 5'-GGAAUUACACUUUC UGGCATT-3', Tsg1: 5'-GACACATACCCATATAACCCC-3', Tsg2: 5'-ACCCG CTTAGATCAAGAAGTA- $3^{\prime}$, AP2 $\alpha-1: 5^{\prime}$-GCAAAGAGGCTGAGATCAAGA- $3^{\prime}$ AP2 $\alpha$-2: $5^{\prime}$-GGGTTATGCTGCCAAGACAGT- $3^{\prime}$ ). The control siRNA duplex was purchased from Sigma-Aldrich (Mission negative control SIC-001). No STAT5A was observed in RCM cells.

Transfection. For protein expression or knockdown, cells were transfected by using a Gene Pulser II electroporation system (Bio-Rad Laboratory) and cultured for at least $20 \mathrm{~h}$. Cells expressing Kit(D814Y)-GFP, PH-GFP or PH(R25C)-GFP were selected in $1 \mathrm{mg} \mathrm{ml}^{-1} \mathrm{G}-418$.

Immunofluorescence. Cells were fixed with $4 \%$ PFA for 20 min at room temperature, or with methanol for $10 \mathrm{~min}$ at $-20^{\circ} \mathrm{C}$, then cyto-centrifuged onto coverslips. Fixed cells were permeabilized and blocked for $30 \mathrm{~min}$ in PBS supplemented with $0.1 \%$ saponin and $3 \%$ bovine serum albumin, and then incubated with a primary and a secondary antibody for $1 \mathrm{~h}$ each. To stain with anti-Akt(pSer473) (Cell Signaling Technology; 193H12), 10\% skimmed milk was used for blocking. After washing with PBS, cells were mounted with Fluomount (DiagnosticBioSystems). For staining endocytic compartments, cells were incubated for $1 \mathrm{~h}$ with $5 \mathrm{\mu g} \mathrm{ml}^{-1}$ AF647-CTXB or $1 \mathrm{mg} \mathrm{ml}^{-1}$ AF647-dextran (Molecular Probes). Confocal images were obtained by a Fluoview FV10i laser scanning microscope with an x60 1.20 N.A. water-immersion objective (Olympus). Composite figures were prepared with Photoshop elements 10 and Illustrator CS6 software (Adobe). Pearson's correlation coefficients (Pearson's R) were calculated with NIH ImageJ Version 1.48v software.

Immunoprecipitation and western blotting. Lysates from RCM, R, pt18, HMC-1 or RBL-2H3 cells were prepared in NP-40 lysis buffer (50 mM HEPES, pH 7.4, 10\% glycerol, $1 \% \mathrm{NP}-40,4 \mathrm{mM}$ EDTA, $100 \mathrm{mM} \mathrm{NaF}, 1 \mu \mathrm{g} \mathrm{ml}^{-1}$ aprotinin, $1 \mu \mathrm{g} \mathrm{ml}^{-1}$ leupeptin, $1 \mu \mathrm{g} \mathrm{ml}^{-1}$ pepstatin A, $1 \mathrm{mM}$ PMSF and $\left.1 \mathrm{mM} \mathrm{Na}_{3} \mathrm{VO}_{4}\right)$. Kit from $2 \times 10^{6}$ cells was immunoprecipitated in each assay. Immunoprecipitation was performed at $4{ }^{\circ} \mathrm{C}$ for $5 \mathrm{~h}$ using protein-G pre-coated with $1 \mu \mathrm{g}$ of antibody. Samples were dissolved in SDS-polyacrylamide gel electrophoresis (SDS-PAGE) sample buffer, and subjected to SDS-PAGE and electro-transferred onto PVDF membranes. Immunodetection was performed by ECL (PerkinElmer). Sequential re-probing of membranes was performed after the complete removal of primary and secondary antibodies in stripping buffer (Thermo Scientific), or inactivation of peroxidase by $0.1 \% \mathrm{NaN}_{3}$. Results were analysed with an LAS-3000 image analyzer with Science Lab software (Fujifilm Co.) or with a c-Digit imaging system with Image Studio Digit software (Licor Biosciences). Uncropped versions of the most important blots are shown in Supplementary Figs 7-11.

Purification of endolysosomal vesicles. Homogenates from RCM or R cells were prepared by re-suspending in hypotonic buffer $(20 \mathrm{mM}$ HEPES pH 7.4, $1 \mathrm{mM}$ $\mathrm{MgCl}_{2}, 4 \mathrm{mM} \mathrm{NaF}, 10 \mathrm{mM}$ EDTA, $0.01 \% \mathrm{NP}-40,1 \mu \mathrm{g} \mathrm{ml}^{-1}$ aprotinin, $1 \mu \mathrm{g} \mathrm{ml}{ }^{-1}$ leupeptin, $1 \mu \mathrm{g} \mathrm{ml}^{-1}$ pepstatin $\mathrm{A}, 1 \mathrm{mM}$ PMSF and $1 \mathrm{mM} \mathrm{Na}_{3} \mathrm{VO}_{4}$ ), and subsequent Dounce homogenization (20 strokes). The suspension was pre-cleared by centrifuging at $1,000 \times g$ for $10 \mathrm{~min}$ at $4{ }^{\circ} \mathrm{C}$. Endolysosomes were immunoprecipitated with anti-LAMP1-coated protein-G Dynabeads (Veritas) and subjected to immunoblotting. Rabbit anti-CD28 antibody was used for control IgG. Immunoprecipitation was performed at $4{ }^{\circ} \mathrm{C}$ for $12 \mathrm{~h}$ using $1.5 \mu \mathrm{g}$ of anti-LAMP1 or anti-CD28. For each assay, $5 \times 10^{6}$ cells were used.

GST-pulldown assay. GST-fusion proteins were expressed in the E. coli BL-21 strain on incubation with $0.5 \mathrm{mM}$ IPTG at $22^{\circ} \mathrm{C}$ for $12 \mathrm{~h}$. The bacteria were lysed by sonication in RIPA buffer (50 mM HEPES, $\mathrm{pH} 7.4,10 \%$ glycerol, $0.1 \%$ SDS $0.25 \%$ sodium deoxycholate, $1 \% \mathrm{NP}-40,4 \mathrm{mM}$ EDTA, $100 \mathrm{mM} \mathrm{NaF}, 1 \mu \mathrm{g} \mathrm{ml}{ }^{-}$ aprotinin, $1 \mu \mathrm{g} \mathrm{ml}^{-1}$ leupeptin, $1 \mu \mathrm{g} \mathrm{ml}^{-1}$ pepstatin A, $1 \mathrm{mM}$ PMSF). GST-fusion proteins were collected on glutathione-Sepharose beads from RIPA lysates and washed four times with RIPA buffer. Pull-down assays were performed at $4{ }^{\circ} \mathrm{C}$ for $5 \mathrm{~h}$ in NP-40 lysates prepared from RCM or R cells. Kit from $1 \times 10^{6}$ cells was pulled down in each assay. After extensively washing with NP-40 lysis buffer, the bead pellets were analysed by SDS-PAGE and immunoblotted with an anti-Kit antibody.

Analysis of protein glycosylation. Following the manufacturer's instructions (New England Biolabs), NP-40 cell lysates were treated with endoglycosidase $\mathrm{H}$ or peptide-N-glycosidase $\mathrm{F}$ for $1 \mathrm{~h}$ at $37^{\circ} \mathrm{C}$. The reactions were stopped with SDSPAGE sample buffer, products were resolved by SDS-PAGE and immunoblotted with an anti-Kit antibody.

\section{References}

1. Besmer, P. et al. A new acute transforming feline retrovirus and relationship of its oncogene v-kit with the protein kinase gene family. Nature 320, 415-421 (1986).

2. Yarden, Y. et al. Human proto-oncogene c-kit: a new cell surface receptor tyrosine kinase for an unidentified ligand. EMBO J. 6, 3341-3351 (1987).

3. Blume-Jensen, P. \& Hunter, T. Oncogenic kinase signalling. Nature 411, 355-365 (2001).

4. Kitamura, Y. \& Hirota, S. Kit as a human oncogenic tyrosine kinase. Cell Mol. Life Sci. 61, 2924-2931 (2004).

5. Rönnstrand, L. Signal transduction via the stem cell factor receptor/c-Kit. Cell Mol. Life Sci. 61, 2535-2548 (2004).

6. Roskoski, R. Structure and regulation of Kit protein-tyrosine kinase-the stem cell factor receptor. Biochem. Biophys. Res. Commun. 338, 1307-1315 (2005).

7. Blume-Jensen, P., Janknecht, R. \& Hunter, T. The kit receptor promotes cell survival via activation of PI 3-kinase and subsequent Akt-mediated phosphorylation of Bad on Ser136. Curr. Biol. 8, 779-782 (1998).

8. Timokhina, I., Kissel, H., Stella, G. \& Besmer, P. Kit signaling through PI 3kinase and Src kinase pathways: an essential role for Racl and JNK activation in mast cell proliferation. EMBO J. 17, 6250-6262 (1998)

9. Broudy et al. Signaling via Src family kinases is required for normal internalization of the receptor c-Kit. Blood 94, 1979-1986 (1999).

10. Ma, P. et al. Balanced interactions between Lyn, the $\mathrm{p} 85 \alpha$ regulatory subunit of class IA phosphatidylinositol-3-kinase, and SHIP are essential for mast cell growth and maturation. Mol. Cell Biol. 31, 4052-4062 (2011).

11. Hirota, S. et al. Gain-of-function mutations of c-kit in human gastrointestinal stromal tumors. Science 279, 577-580 (1998).

12. Furitsu, T. et al. Identification of mutations in the coding sequence of the proto-oncogene c-kit in a human mast cell leukemia cell line causing ligandindependent activation of c-kit product. J. Clin. Invest. 92, 1736-1744 (1993).

13. Boissan, M., Feger, F., Guillosson, J. J. \& Arock, M. c-Kit and c-kit mutations in mastocytosis and other hematological diseases. J. Leukoc. Biol. 67, 135-148 (2000).

14. Lasota, J. \& Miettinen, M. Clinical significance of oncogenic KIT and PDGFRA mutations in gastrointestinal stromal tumours. Histopathology 53, 245-266 (2008).

15. Chian, R. et al. Phosphatidylinositol 3 kinase contributes to the transformation of hematopoietic cells by the D816V c-Kit mutant. Blood 98, 1365-1373 (2001).

16. Aichberger, K. J. et al. Identification of proapoptotic Bim as a tumor suppressor in neoplastic mast cells: role of KIT D816V and effects of various targeted drugs. Blood 114, 5342-5351 (2009).

17. Jahn, T., Leifheit, E., Gooch, S., Sindhu, S. \& Weinberg, K. Lipid rafts are required for Kit survival and proliferation signals. Blood 110, 1739-1747 (2007).

18. Gordon, P. M. \& Fisher, D. E. Role for the proapoptotic factor BIM in mediating imatinib-induced apoptosis in a c-KIT-dependent gastrointestinal stromal tumor cell line. J. Biol. Chem. 285, 14109-14114 (2010).

19. Ning, Z. Q., Li, J. \& Arceci, R. J. Signal transducer and activator of transcription 3 activation is required for Asp816 mutant c-Kit-mediated cytokineindependent survival and proliferation in human leukemia cells. Blood 97, 3559-3567 (2001). 
20. Baumgartner, C. et al. Expression of activated STAT5 in neoplastic mast cells in systemic mastocytosis: subcellular distribution and role of the transforming oncoprotein KIT D816V. Am. J. Pathol. 175, 2416-2429 (2009).

21. Chaix, A. et al. Mechanisms of STAT protein activation by oncogenic KIT mutants in neoplastic mast cells. J. Biol. Chem. 286, 5956-5966 (2009).

22. Ronchetti, D. et al. Deregulated FGFR3 mutants in multiple myeloma cell lines with $\mathrm{t}(4 ; 14)$ : comparative analysis of $\mathrm{Y} 373 \mathrm{C}, \mathrm{K} 650 \mathrm{E}$ and the novel G384D mutations. Oncogene 20, 3553-3562 (2003).

23. Chung, B. M. et al. Aberrant trafficking of NSCLC-associated EGFR mutants through the endocytic recycling pathway promotes interaction with Src. BMC. Cell Biol. 10, 84 (2009).

24. Joffre, C. et al. A direct role for Met endocytosis in tumorigenesis. Nat. Cell Biol. 13, 827-837 (2011).

25. Williams, A. B. et al. Fluvastatin inhibits FLT3 glycosylation in human and murine cells and prolongs survival of mice with FLT3/ITD leukemia. Blood 120, 3069-3079 (2012).

26. Choudhary, C. et al. Mislocalized activation of oncogenic RTKs switches downstream signaling outcomes. Mol. Cell 36, 326-339 (2009).

27. Toffalini, F. \& Demoulin, J. B. New insights into the mechanisms of hematopoietic cell transformation by activated receptor tyrosine kinases. Blood 116, 2429-2437 (2010).

28. Mitsui, H. et al. Development of human mast cells from umbilical cord blood cells by recombinant human and murine c-kit ligand. Proc. Natl Acad. Sci. USA 90, 735-739 (1993).

29. Growney, J. D. et al. Activation mutations of human c-KIT resistant to imatinib mesylate are sensitive to the tyrosine kinase inhibitor PKC412. Blood 106, 721-724 (2005).

30. Xiang, Z., Kreisel, F., Cain, J., Colson, A. L. \& Tomasson, M. H. Neoplasia driven by mutant c-KIT is mediated by intracellular, not plasma membrane, receptor signaling. Mol. Cell Biol. 27, 267-282 (2007).

31. Tabone-Eglinger, S. et al. KIT mutations induce intracellular retention and activation of an immature form of the KIT protein in gastrointestinal stromal tumors. Clin. Cancer Res. 14, 12285-12294 (2008).

32. Bougherara, H. et al. The aberrant localization of oncogenic kit tyrosine kinase receptor mutants is reversed on specific inhibitory treatment. Mol. Cancer Res. 7, 1525-1533 (2009).

33. Jahn, T. et al. Analysing c-kit internalization using a functional c-kit-EGFP chimera containing the fluorochrome within the extracellular domain. Oncogene 21, 4508-4520 (2002).

34. Kon, S. et al. Smap1 deficiency perturbs receptor trafficking and predisposes mice to myelodysplasia. J. Clin. Invest. 123, 1123-1137 (2013).

35. Mercer, J. \& Helenius, A. Virus entry by macropinocytosis. Nat. Cell Biol. 11, 510-520 (2009).

36. Naal, R. M., Holowka, E. P., Baird, B. \& Holowka, D. Antigen-stimulated trafficking from the recycling compartment to the plasma membrane in RBL mast cells. Traffic 4, 190-200 (2003).

37. Sigismund, S. et al. Clathrin-mediated internalization is essential for sustained EGFR signaling but dispensable for degradation. Dev. Cell 15, 209-219 (2008).

38. Di Guglielmo, G. M., Le Roy, C., Goodfellow, A. F. \& Wrana, J. L. Distinct endocytic pathways regulate TGF-beta receptor signalling and turnover. Nat. Cell Biol. 5, 410-421 (2003).

39. Sigismund, S. et al. Endocytosis and signaling: cell logistics shape the eukaryotic cell plan. Physiol. Rev. 92, 273-366 (2012).

40. Heuser, J. E. \& Anderson, R. G. Hypertonic media inhibit receptor-mediated endocytosis by blocking clathrin-coated pit formation. J. Cell Biol. 108, 389-400 (1989).

41. von Kleist, L. et al. Role of the clathrin terminal domain in regulating coated pit dynamics revealed by small molecule inhibition. Cell 146, 471-484 (2011).

42. Orlandi, P. A. \& Fishman, P. H. Filipin-dependent inhibition of cholera toxin: evidence for toxin internalization and activation through caveolae-like domains. J. Cell Biol. 141, 905-915 (1998).

43. Acconcia, F., Sigismund, S. \& Polo, S. Ubiquitin in trafficking: The network at work. Exp. Cell Res. 315, 1610-1618 (2009).

44. Hayer, A. et al. Caveolin-1 is ubiquitinated and targeted to intralumenal vesicles in endolysosomes for degradation. J. Cell Biol. 191, 615-629 (2010).

45. Yee, N. S., Hsiau, C. W., Serve, H., Vosseller, K. \& Besmer, P. Mechanism of down-regulation of c-kit receptor. Roles of receptor tyrosine kinase, phosphatidylinositol $3^{\prime}$-kinase, and protein kinase C. J. Biol. Chem. 269, 31991-31998 (1994)

46. Stuffers, S., Wegner, S. C., Stenmark, H. \& Brech, A. Multivesicular endosome biogenesis in the absence of ESCRTs. Traffic 10, 925-937 (2009).

47. Mali, R. S. et al. Rho kinase regulates the survival and transformation of cells bearing oncogenic forms of KIT, FLT3, and BCR-ABL. Cancer Cell 20, 357-369 (2011).

48. Joly, M., Kazlauskas, A., Fay, F. S. \& Corvera, S. Disruption of PDGF receptor trafficking by mutation of its PI-3 kinase binding sites. Science 263, 684-687 (1994).
49. Er, E. E., Mendoza, M. C., Mackey, A. M., Rameh, L. E. \& Blenis, J. AKT facilitates EGFR trafficking and degradation by phosphorylating and activating PIKfyve. Sci. Signal 6, ra45 (2013).

50. Ménard, L., Parker, P. J. \& Kermorgant, S. Receptor tyrosine kinase c-Met controls the cytoskeleton from different endosomes via different pathways. Nat. Commun. 5, 3907 (2014).

51. Wang, Y., Pennock, S. D., Chen, X., Kazlauskas, A. \& Wang, Z. Platelet-derived growth factor receptor-mediated signal transduction from endosomes. J. Biol. Chem. 279, 8038-8046 (2004).

52. Sun, Y., Hedman, A. C., Tan, X., Schill, N. J. \& Anderson, R. A. Endosomal type I $\gamma$ PIP 5-kinase controls EGF receptor lysosomal sorting. Dev. Cell 25, 144-155 (2013).

53. Kim, M. S., Rådinger, M. \& Gilfillan, A. M. The multiple roles of phosphoinositide 3-kinase in mast cell biology. Trends Immunol. 29, 493-501 (2008).

54. Várnai, P. \& Balla, T. Visualization of phosphoinositides that bind pleckstrin homology domains: calcium- and agonist-induced dynamic changes and relationship to myo-[3H] inositol-labeled phosphoinositide pools. J. Cell Biol. 143, 501-510 (1998).

55. Clague, M. J., Urbé, S., Aniento, F. \& Gruenberg, J. Vacuolar ATPase activity is required for endosomal carrier vesicle formation. J. Biol. Chem. 269, 21-24 (1994).

56. Griffiths, G., Quinn, P. \& Warren, G. Dissection of the Golgi complex. I. Monensin inhibits the transport of viral membrane proteins from medial to trans Golgi cisternae in baby hamster kidney cells infected with Semliki Forest virus. J. Cell Biol. 96, 835-850 (1983).

57. Helenius, A. \& Aebi, M. Roles of N-linked glycans in the endoplasmic reticulum. Annu. Rev. Biochem. 73, 1019-1049 (2004).

58. Klausner, R. D., Donaldson, J. G. \& Lippincott-Schwartz, J. Brefeldin A: insights into the control of membrane traffic and organelle structure. J. Cell Biol. 116, 1071-1080 (1992).

59. Schmidt-Arras, D. et al. Oncogenic deletion mutants of gp130 signal from intracellular compartments. J. Cell Sci. 127, 341-353 (2014).

60. Kazi, J. U., Agarwal, S., Sun, J., Bracco, E. \& Rönnstrand, L. Src-like-adaptor protein (SLAP) differentially regulates normal and oncogenic c-Kit signaling. J. Cell Sci. 127, 653-662 (2014).

61. Cremona, O. et al. Essential role of phosphoinositide metabolism in synaptic vesicle recycling. Cell 99, 179-188 (1999).

62. Shin, H. W. et al. An enzymatic cascade of Rab5 effectors regulates phosphoinositide turnover in the endocytic pathway. J. Cell Biol. 170, 607-618 (2005).

63. Rong, Y. et al. Clathrin and phosphatidylinositol-4,5-bisphosphate regulate autophagic lysosome reformation. Nat. Cell Biol. 14, 924-934 (2012).

64. Sridhar, S. et al. The lipid kinase PI4KIII $\beta$ preserves lysosomal identity. EMBO J. 32, 324-339 (2013).

65. Bandi et al. E3 ligase-defective $\mathrm{Cbl}$ mutants lead to a generalized mastocytosis and myeloproliferative disease. Blood 114, 4197-4208 (2009).

66. Zeng, S., Xu, Z., Lipkowitz, S. \& Longley, J. B. Regulation of stem cell factor receptor signaling by $\mathrm{Cbl}$ family proteins (Cbl-b/c-Cbl). Blood 105, 226-232 (2005).

67. Zermati, Y. et al. Effect of tyrosine kinase inhibitor STI571 on the kinase activity of wild-type and various mutated c-kit receptors found in mast cell neoplasms. Oncogene 22, 660-664 (2003).

68. Bauer, S., Duensing, A., Demetri, G. D. \& Fletcher, J. A. KIT oncogenic signaling mechanisms in imatinib-resistant gastrointestinal stromal tumor: PI3-kinase/AKT is a crucial survival pathway. Oncogene 26, 7560-7568 (2007).

69. Edris et al. Anti-KIT monoclonal antibody inhibits imatinib-resistant gastrointestinal stromal tumor growth. Proc. Natl Acad. Sci. USA 110, 3501-3506 (2013).

70. Scaltriti et al. Lapatinib, a HER2 tyrosine kinase inhibitor, induces stabilization and accumulation of HER2 and potentiates trastuzumab-dependent cell cytotoxicity. Oncogene 28, 803-814 (2009).

\section{Acknowledgements}

We thank Dr Hirohisa Saito and Dr Kenji Matsumoto (National Center for Child Health and Development) for providing HMC-1 cells, Dr Ko Okumura (Juntendo University) for RBL-2H3 cells, Dr Ryo Goitsuka (Tokyo University of Science) for pt18 cells, Dr Hajime Karasuyama (Tokyo Medical and Dental University) for the pBCMGS vector, Dr Masayuki Oda (Kyoto Prefectural University) for the GST-SH2 expression vector, Dr Tamás Balla (National Institutes of Health) for the PH-GFP expression vector and Dr Toshinori Nakayama (Chiba University) for an anti-phosphotyrosine antibody. We are grateful to Dr Daijiro Sugiyama (Daiichi-Sankyo), Dr Takachika Azuma and Dr Yasushi Hara (Tokyo University of Science) for their helpful advice and sharing of materials throughout this study. This work was supported by a grant-in-aid for Scientific Research from the Japanese Ministry of Education, Culture, Sports, Science and Technology to R.A., and a research grant from the NOVARTIS FOUNDATION (Japan) for the Promotion of Science. 


\section{Author contributions}

Y.O. conceived, designed, performed and analysed data from all experiments, and wrote the paper. S.T. and E.W. characterized R cells as mast-like cells in vivo and in vitro by flow cytometry, histo-cytochemical staining, electron microscopy, proliferation assays and microarray analyses, and edited the manuscript. S.S. and S.O performed immunoblotting, immunoprecipitation assays, in vitro GST-pulldown assays and RNA interference experiments. H.E. advised on the design of the in vitro experiments and edited the manuscript. R.A. conceived and supervised the project, analysed data and wrote the manuscript.

\section{Additional information}

Supplementary Information accompanies this paper at http://www.nature.com/

naturecommunications

Competing financial interests: The authors declare no competing financial interests.
Reprints and permission information is available online at http://npg.nature.com/ reprintsandpermissions/

How to cite this article: Obata, Y. et al. Oncogenic Kit signals on endolysosomes and endoplasmic reticulum are essential for neoplastic mast cell proliferation. Nat. Commun. 5:5715 doi: 10.1038/ncomms6715 (2014).

\section{(c) (1)}

This work is licensed under a Creative Commons Attribution 4.0 International License. The images or other third party material in this article are included in the article's Creative Commons license, unless indicated otherwise in the credit line; if the material is not included under the Creative Commons license, users will need to obtain permission from the license holder to reproduce the material. To view a copy of this license, visit http://creativecommons.org/licenses/by/4.0/ 